\title{
RESEARCH
}

Open Access

\section{A20 deficiency causes spontaneous neuroinflammation in mice}

\author{
Renata Padilha Guedes ${ }^{1,3}$, Eva Csizmadia ${ }^{1}$, Herwig P Moll ${ }^{1}$, Averil Ma², Christiane Ferran ${ }^{1}$ \\ and Cleide Gonçalves da Silva ${ }^{1 *}$
}

\begin{abstract}
Background: A20 (TNFAIP3) is a pleiotropic NFKB-dependent gene that terminates NFKB activation in response to inflammatory stimuli. The potent anti-inflammatory properties of A20 are well characterized in several organs. However, little is known about its role in the brain. In this study, we investigated the brain phenotype of A20 heterozygous (HT) and knockout (KO) mice.

Methods: The inflammatory status of A20 wild type (WT), HT and KO brain was determined by immunostaining, quantitative PCR, and Western blot analysis. Cytokines secretion was evaluated by ELISA. Quantitative results were statistically analyzed by ANOVA followed by a post-hoc test.

Results: Total loss of A20 caused remarkable reactive microgliosis and astrogliosis, as determined by F4/80 and GFAP immunostaining. Glial activation correlated with significantly higher mRNA and protein levels of the pro-inflammatory molecules TNF, IL-6, and MCP-1 in cerebral cortex and hippocampus of A20 KO, as compared to WT. Basal and TNF/LPS-induced cytokine production was significantly higher in A20 deficient mouse primary astrocytes and in a mouse microglia cell line. Brain endothelium of A20 KO mice demonstrated baseline activation as shown by increased vascular immunostaining for ICAM-1 and VCAM-1, and mRNA levels of E-selectin. In addition, total loss of A2O increased basal brain oxidative/nitrosative stress, as indicated by higher iNOS and NADPH oxidase subunit gp $91^{\text {phox }}$ levels, correlating with increased protein nitration, gauged by nitrotyrosine immunostaining. Notably, we also observed lower neurofilaments immunostaining in A20 KO brains, suggesting higher susceptibility to axonal injury. Importantly, A20 HT brains showed an intermediate phenotype, exhibiting considerable, albeit not statistically significant, increase in markers of basal inflammation when compared to WT.

Conclusions: This is the first characterization of spontaneous neuroinflammation caused by total or partial loss of A20, suggesting its key role in maintenance of nervous tissue homeostasis, particularly control of inflammation. Remarkably, mere partial loss of A20 was sufficient to cause chronic, spontaneous low-grade cerebral inflammation, which could sensitize these animals to neurodegenerative diseases. These findings carry strong clinical relevance in that they question implication of identified A20 SNPs that lower A20 expression/function (phenocopying A20 HT mice) in the pathophysiology of neuroinflammatory diseases.
\end{abstract}

Keywords: TNFAIP3/A20, Neuroinflammation, Reactive gliosis, Inflammatory cytokines, Oxidative stress

\footnotetext{
* Correspondence: cdasilva@bidmc.harvard.edu

'Division of Vascular Surgery, Center for Vascular Biology Research and the Transplant Institute, Department of Surgery, Beth Israel Deaconess Medical Center, Harvard Medical School, Boston, MA, USA

Full list of author information is available at the end of the article
} 


\section{Background}

Neuroinflammation is a common pathogenic culprit of several neurodegenerative diseases including Alzheimer's Disease (AD) [1], Parkinson's Disease (PD) [2], multiple sclerosis (MS) [3], stroke [4] and neuropsychiatric diseases such as depression, schizophrenia and autism [5,6]. Injury to the central nervous system (CNS), whether metabolic, structural, auto-immune, ischemic, infectious or mechanical, results in increased production of pro-inflammatory cytokines such as TNF, IL- $1 \beta$ and IL- 6 , and of neurotoxic molecules such as nitric oxide (NO), by activated microglia and astrocytes. Such pro-inflammatory environment culminates in cell death and cerebral tissue damage $[7,8]$.

Anti-inflammatory therapies including IL-1 receptor antagonist, IL-1 $\beta$ inhibitors and NSAIDs have shown some benefit in reducing post-stroke neurodegenerative lesions, and in decreasing incidence of AD or PD [9-11]. However, widespread use of these therapies must be cautioned by their inhibitory effect on $\mathrm{NFKB}$, a transcription factor that regulates expression of many pro-inflammatory mediators, all the while promoting the upregulation of protective and regenerative molecules in the CNS [12]. Therefore, a better understanding of the molecular signature of neuroinflammatory diseases is required in order to identify safe, effective and possibly disease-specific therapeutic targets.

A20 (TNF alpha-induced protein 3, TNFAIP3), a pleiotropic NFKB-dependent gene [13] expressed in a variety of tissues and cell types, including the human brain [14], encodes a ubiquitin-editing enzyme that is essential for termination of $\mathrm{NF} K \mathrm{~B}$ activation in response to multiple stimuli such as IL-1 $\beta$, TNF, IL-6, CD40 and lipopolysaccharide (LPS) [15-17]. The potent anti-inflammatory role of A20 is exemplified by the phenotype of A20 knockout (KO) mice. These mice rapidly become cachectic and die within three to five weeks of age, as a result of uncontrolled inflammation in several organs [18]. In contrast to its ubiquitous anti-inflammatory function, A20's effect on apoptosis is cell type specific. A20 exhibits potent anti-apoptotic properties in endothelial cells (EC), hepatocytes and pancreatic $\beta$-cells, through several mechanisms including blockade of the caspase cascade at the level of caspase 8, and preservation of mitochondrion integrity [19]. On the other hand, A20 promotes vascular smooth muscle cells apoptosis through a NO-dependent mechanism [20]. In addition, overexpression of A20 protects livers and kidneys from ischemia reperfusion injury, in part by upregulating peroxisome proliferator associated receptor alpha, channeling lipid metabolism away from lipid peroxidation towards mitochondrial $\beta$-oxidation, which results in increased ATP generation [21,22].

Little is known about the role of A20 in the CNS. Evidence from the literature suggest that increased expression of A20 is neuroprotective in animal models of epilepsy [23] and of focal cerebral ischemia, in part by limiting ischemic damage and containing TNF-induced neuronal apoptosis [24]. However, these gain-of-function studies did not address the physiological role of A20 nor its involvement in maintaining homeostasis and, in particular, containing inflammation in the CNS. In more recent studies, mice with neuroectodermal (astrocytes, neurons and oligodendrocytes) specific A20 KO failed to show increased CNS inflammation at baseline [25] and did not demonstrate larger ischemic infarcts following middle cerebral artery occlusion [26], when compared to their wild type (WT) littermates. However, CNS specific A20 KO did develop an aggravated form of auto-immune encephalomyelitis, which was attributed to astrocytic loss of A20, further fueling controversy about A20's function in the CNS [25]. In order to better delineate the physiological role of A20 in modulating CNS inflammation, we phenotyped the cerebral inflammatory pattern of full A20 KO and heterozygous (HT) mice. We reasoned that this approach carries greater clinical relevance than cell typespecific $\mathrm{KO}$ of this gene, as it would enable us to gauge the impact of A20 on CNS generators of inflammation (microglial cells, astrocytes), as well as CNS targets of inflammation (neurons, endothelial cells). This study is timely given the many A20 single SNPs causing decreased expression or function of this gene that have been associated with numerous auto-immune and inflammatory diseases [25,27-30].

\section{Experimental procedures}

Reagents: Human recombinant TNF was purchased from R\&D Systems (Minneapolis, MN, USA). LPS (Lipopolysaccharides from Escherichia coli 055:B5), and FBS were obtained from Sigma-Aldrich Co. (St. Louis, MO, USA).

\section{Mice}

Four to five-week-old A20 KO, HT and WT littermate control mice [18] were used for forebrain isolation. Following anesthesia, mice were sacrificed by decapitation, and their brains recovered and fixed for analysis by immunohistochemistry (IHC) and immunofluorescence (IF). Alternatively, cerebral cortex (CX) and hippocampus (HC) were isolated for mRNA and protein isolation. For primary astrocyte isolation and culture, brains from one to threeday-old pups were used. Animals received humane care according to the criteria outlined in the Guide for the Care and Use of Laboratory Animals. Beth Israel Deaconess Medical Center Institutional Animal Care and Use Committee approved all research protocols.

\section{Cell culture}

Primary astrocytes were prepared from forebrain of neonatal mice (one to three-day-old) according to a modified 
method of McCarthy and De Vellis [31]. Purity of astrocyte preparation was $>95 \%$. In brief, cerebral hemispheres were freed from the meninges and the forebrain was dissociated mechanically using fire-polished Pasteur pipets. Mixed brain cells were plated in DMEM containing 10\% FBS, and antibiotics (Mediatech, Inc., Manassas, VA, USA). Cells were cultured for seven to ten days until confluent in a humidified atmosphere enriched with $5 \% \mathrm{CO}_{2}$. Contaminating oligodendrocytes and microglial cells were eliminated from the astrocytic monolayer by placing culture flasks on a rotary shaker at $800 \mathrm{rpm}$ overnight. Astrocyte monolayers were then trypsinized and cells plated in 24-well plates and cultured to confluency for seven to ten days before being used in experiments. The mouse microglia cell line N13 (kind gift of Dr. Di Virgilio, University of Ferrara, Italy) and mouse primary astrocytes purchased from ScienCell Research Laboratories (Carlsbad, CA, USA) were used in RNA silencing experiments.

\section{Western blot}

Tissue lysates (40 to $60 \mu \mathrm{g}$ protein) were separated under reducing conditions by SDS-PAGE (Bio-Rad Laboratories, Hercules, CA, USA) [32], and transferred to Polyvinylidene fluoride (PVDF) membranes (PerkinElmer Life Science, Whaltham, MA, USA) by semi-dry electroblotting. Membranes were probed with mouse anti-gp91 ${ }^{\text {phox }}(\mathrm{BD}$ Pharmigen, San Diego, CA, USA), mouse anti-glyceraldehyde 3-phosphate dehydrogenase (GAPDH) (EMD chemicals), mouse anti- $\beta$ actin and rabbit anti-IkB $\alpha$ (Santa Cruz Biotechnology, Inc., Santa Cruz, CA, USA). Appropriate secondary horseradish peroxidase (HRP)-conjugated antibodies were used (Thermo Scientific, Rockford, IL, USA). Protein bands were detected with enhanced chemiluminescence kit (ECL) (PerkinElmer Life Science, Waltham, MA, USA) followed by exposure to the autoradiography film. Immunoblots were scanned and the intensity of the bands was quantified by densitometry using ImageJ 1.41 (US National Institutes of Health, Bethesda, MD, USA).

\section{Silencing RNA (siRNA)}

N13 microglia cells and mouse primary astrocytes (ScienCell Research Laboratories, Carlsbad, CA, USA) were transfected with predesigned A20 silencing RNA probes (A20 siRNA) or All Start Negative Control siRNA (C siRNA), using Hiperfect transfection reagent purchased from Qiagen (Valencia, CA, USA). Transfections were carried out according to the manufacturer's transfection protocol. Experiments were performed 24 hours after transfection. Efficiency of gene knockdown was evaluated by qPCR in non-treated and LPS ( $1 \mu \mathrm{g} / \mathrm{mL}$ for 1 hour) treated cells.

\section{TNF and IL-6 secretion}

Cell culture medium was changed to serum-free medium, then cells were stimulated with either TNF or LPS in order to mimic inflammation. Supernatants were then recovered, and analyzed for IL- 6 and TNF content by ELISA, using mouse IL-6 and TNF ELISA Ready-SET-Go! (eBioscience, San Diego, CA, USA), according to manufacturer's instruction. Results were normalized by protein content. Cell cultures incubated in medium alone were used as non-stimulated controls.

\section{Quantitative reverse transcriptase-polymerase chain reaction (qPCR)}

mRNA from CX and $\mathrm{HC}$ and from primary astrocytes and the mouse microglia cell line N13 was isolated using RNAse spin columns (Qiagen, Valencia, CA, USA), and cDNA was synthesized using iScript cDNA synthesis kit (Bio-Rad, Hercules, CA, USA). Real-time PCR (qPCR) was performed using iTaq Fast SYBR Green Supermix with ROX (Bio-Rad, Hercules, CA, USA) and gene specific primers (Table 1) or TaqMan Mm00627280_m1 (tnfaip3), Mm00607939_s1 (ßactin), and ABI 7500 Fast Real-time PCR System (Applied Biosystems, Inc., Foster City, CA, USA). Comparative threshold cycle (Ct) method was used to perform relative quantification of $\mathrm{qPCR}$ results. mRNA expression of target genes A1, TNF, IL-6, inducible NOS (iNOS), endothelial NO synthase (eNOS), neuronal NO synthase (nNOS), E-selectin, monocyte chemoattractant protein 1 (MCP-1), glial fibrillary acidic protein (GFAP), nuclear factor erythroid 2 related factor 2 (Nrf2), IкB $\alpha$, gp91 ${ }^{\text {phox }}$ and heme oxygenase-1 (HO-1) was normalized to that of the housekeeping gene $\beta$ actin. Data are expressed as fold change of levels noted in WT mice.

Immunohistochemistry (IHC) and immunofluorescence (IF) Brains were processed for IHC and IF as described [33]. In brief, $2,000-\mu \mathrm{m}$ coronal slices were zinc-fixed (BD Pharmigen, San Diego, CA, USA) for 48 hours at room temperature, dehydrated in a tissue processor and embedded in paraffin for sectioning, before being sectioned into 6 - $\mu \mathrm{m}$ thickness. For IHC, sections were de-paraffinized, rehydrated, fixed with cold acetone:formalin 95:5 (vol/vol) for 3 minutes, then incubated with horse serum $(7 \%$ in PBS) prior to overnight incubation at $4^{\circ} \mathrm{C}$ with hamster anti-ICAM-1 and rat anti-VCAM-1 (BD Pharmigen, San Diego, CA, USA), rabbit anti-iNOS and anti-IL-6 (Abcam Inc., Cambridge, MA, USA), and rabbit anti-GFAP (Dako, Carpinteria, CA, USA). Alternatively, sections were fixed with cold $2 \%$ paraformaldehyde for 10 minutes prior to overnight incubation with mouse anti-nitrotyrosine (Santa Cruz Biotechnology, Inc., Santa Cruz, CA, USA), rat antiF4/80 (AbDSerotec, Raleigh, NC, USA), rabbit anti-TNF alpha (Novus Biologicals, Littleton, $\mathrm{CO}$ ) and hamster anti-MCP-1 (BD Pharmigen, Franklin Lakes, NJ, USA). Sections were then treated with $\mathrm{H}_{2} \mathrm{O}_{2}$ 1:100 in PBS for 10 minutes, incubated with the appropriate secondary IgG antibodies followed by $\mathrm{ABC}$ (avidin-biotin complex) 
Table 1 List of primers used in real-time PCR

\begin{tabular}{|c|c|c|c|c|}
\hline Gene & Definition & Accession & Forward & Reverse \\
\hline IL-6 & Mus musculus interleukin 6 & NM_031168.1 & GACAACCACGGCCTTCCCTACTTC & TCATTTCCACGATTTCCCAGAGA \\
\hline TNF & Mus musculus tumor necrosis factor & NM_013693.2 & GACAAGGCTGCCCCGACTACG & CTTGGGGCAGGGGCTCTTGAC \\
\hline iNOS & $\begin{array}{l}\text { Mus musculus nitric oxide synthase } 2 \text {, } \\
\text { inducible (Nos2) }\end{array}$ & NM_010927.3 & AACAGAGCCCTCAGCAGCATCCAT & CCAGGTGTTCCCCAGGCAGGTAG \\
\hline eNOS & $\begin{array}{l}\text { Mus musculus nitric oxide synthase } 3 \text {, } \\
\text { endothelial cell (Nos3) }\end{array}$ & NM_008713.4 & TCACTTCGTTCGGTTGACCA & CCTTCAAGATTTAGGCCGACCC \\
\hline $\mathrm{nNOS}$ & $\begin{array}{l}\text { Mus musculus nitric oxide synthase } 1 \text {, } \\
\text { neuronal (Nos1) }\end{array}$ & NM_008712.2 & GCCGCCAAAACCTGCAAAGTCCTA & CGCGTCCTCCAGCCGTTCAAT \\
\hline GFAP & $\begin{array}{l}\text { Mus musculus glial fibrillary acidic protein } \\
\text { (Gfap), transcript variant } 1 \text { and variant } 2\end{array}$ & $\begin{array}{l}\text { NM_001131020.1 } \\
\text { NM_010277.3 }\end{array}$ & TACCATGCCACGCTTCTCCTTGTC & ACGCTCGCTCGCCCGTGTCTCCT \\
\hline E-selectin & $\begin{array}{l}\text { Mus musculus selectin, endothelial cell } \\
\text { (Sele) }\end{array}$ & NM_011345.2 & CTTGACGTCCCGGGAAAGATGAAC & GGGACGGGTGGGGCTGACTGG \\
\hline MCP-1 & $\begin{array}{l}\text { Mus musculus chemokine (C-C motif) } \\
\text { ligand } 2 \text { (CCl2) }\end{array}$ & NM_011333.3 & GTTAACGCCCCACTCACCT & AAAAACTACAGCTTCTTTGGACACCT \\
\hline A1 & $\begin{array}{l}\text { Mus musculus B-cell leukemia/lymphoma } 2 \\
\text { related protein A1a (Bcl2a1a) }\end{array}$ & NM_009742.3 & TGGGGGTGTTCTCCTCAAAAAA & AAGCCATCTTCCCAACCTCCATTC \\
\hline $\mathbb{I L}-1 \beta$ & Mus musculus interleukin 1 beta & NM_008361.3 & AAATCTCGCAGCAGCACATCAA & CCACGGGAAAGACACAGGTAGC \\
\hline Nrf2 & $\begin{array}{l}\text { Mus musculus nuclear factor, erythroid } \\
\text { derived 2, like } 2 \text { (Nfe2l2) }\end{array}$ & NM_010902.3 & CCGGCCCAGCACATCCAGACAGAC & GGGATATCCAGGGCAAGCGACTCA \\
\hline Gp91phox & $\begin{array}{l}\text { Mus musculus cytochrome b245, beta } \\
\text { polypeptide (Cybb) }\end{array}$ & NM_007807.5 & CAAGTGCCCCAAGGTATCCAAGTT & TGAATAGCCCCTCCGTCCAGTCTC \\
\hline $\mathrm{HO}-1$ & $\begin{array}{l}\text { Mus musculus heme oxygenase (decycling) } \\
1 \text { (Hmox } 1)\end{array}$ & NM_010442.2 & GCCCACGCATATACCCGCTACCT & CCATGGCCTTCTGTGCAATCTTCT \\
\hline $\mathrm{IkBa}$ & $\begin{array}{l}\text { Nuclear factor of kappa light polypeptide } \\
\text { gene enhancer in B-cells inhibitor, alpha }\end{array}$ & NM_010907 & СTACACCTTGCCTGTGAGCA & TCCTGAGCATTGACATCAGC \\
\hline
\end{tabular}

reagent (Vector Laboratories, Burlingame, CA, USA), then detected by ImmPACT 3,3'-diaminobenzidine tetrahydrochloride (DAB) peroxidase substrate (Vector Laboratories, Burlingame, CA, USA). Negative controls using only secondary antibodies confirm the absence of non-specific immunostaining (Additional file 1: Figure S1). For IF, sections were fixed with $2 \%$ cold paraformaldehyde for $10 \mathrm{mi}-$ nutes prior to overnight incubation with rabbit anti-Nrf2 (Abcam plc., Cambridge, MA, USA), rabbit anti-IL-6, rat anti-F4/80 and goat anti-GFAP (Santa Cruz, Biotechnology, inc., Dallas, TX, USA), followed by appropriate Alexa Fluor 488 (green) and 594 (red) conjugated secondary antibodies (Invitrogen, Carlsbad, CA, USA).

\section{Statistical analysis}

Results are presented as mean \pm standard error of mean (SEM). Statistical analysis was performed on Prism 5 for Mac (GraphPad Software, Inc., La Jolla, CA, USA). Data were analyzed by one or two way analysis of variance (ANOVA) followed by post-hoc Tukey or Bonferroni, respectively, when F was significant. Alternatively, results were analyzed by a non-parametric Kruskal-Wallis analysis followed by Dunn's multiple comparison tests when variances differed significantly. Differences between groups were rated significant at a probability error $(P)<0.05$.

\section{Results}

Baseline A20 mRNA expression and NFKB activation in mouse cerebral cortex and hippocampus

We first probed for expression and distribution of A20 in normal and A20 deficient mouse brain. By qPCR, we demonstrated that A20 mRNA was detected in comparable amounts in $\mathrm{CX}$ and $\mathrm{HC}$ of WT mice (Figure 1A). As expected, A20 mRNA was undetectable in the brain of $\mathrm{KO}$ mice and showed 50\% reduction in the brain of HT mice (Figure 1A). A20 wipeout correlated with higher $\mathrm{NF} \mathrm{B}$ activation in cerebral cortex and hippocampus of $\mathrm{KO}$ versus WT mice, as evidenced by remarkably lower $\mathrm{I} \kappa \mathrm{B} \alpha$ protein levels, indicative of amplified degradation (Figure $1 \mathrm{~B}$ ) while $\mathrm{I} \kappa \mathrm{B} \alpha$ protein levels were intermediate in $\mathrm{CX}$ and $\mathrm{HC}$ of $\mathrm{HT}$ mice. Corroborating heightened NFKB activation in the brains of A20 KO mice, we noted significantly higher mRNA levels of $\mathrm{I} \kappa \mathrm{B} \alpha$, itself a prime NFkB-dependent gene, when compared to WT brains, with again HT brains showing intermediate results (Figure 1C).

Total and partial loss of A20 causes reactive microgliosis and astrogliosis

Having confirmed absence and decreased expression of A20 in brains of $\mathrm{KO}$ and $\mathrm{HT}$ mice, respectively, we 


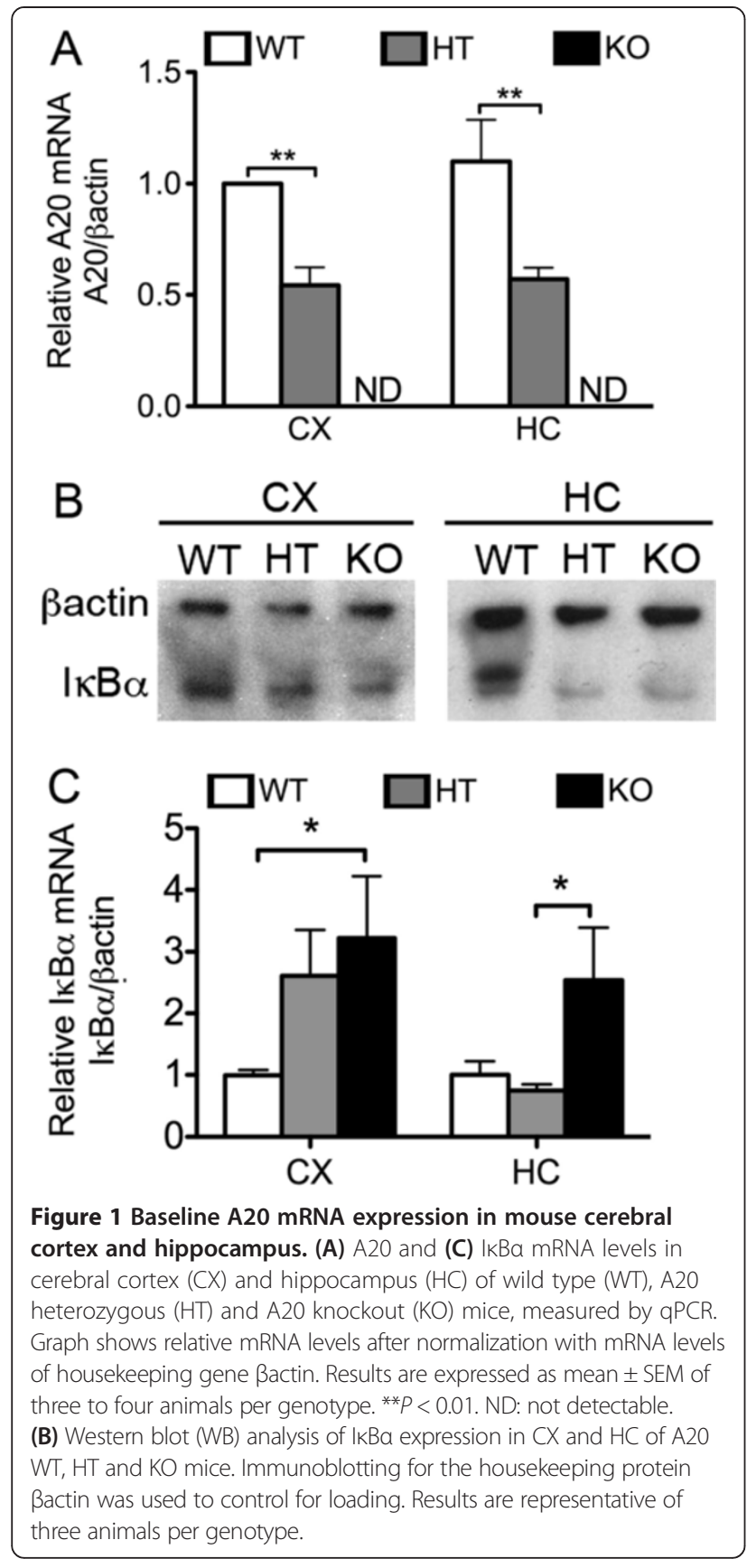

evaluated the impact of total or partial loss of A20 on microglia and astrocytes activation. Microglia, the resident macrophages of the CNS, and astrocytes, the most abundant glial cell population, respond to injury and inflammation by assuming an activated phenotype defined by characteristic changes in morphology and gene expression, and by increased propensity for migration and proliferation $[34,35]$.

Immunohistochemistry analysis of mouse brain sections using a macrophage/microglia cell surface marker F4/80 [36] revealed increased number of activated microglia throughout the A20 KO brain, as evidenced by their typical hypertrophied phenotype, that is enlarged cells with shorter and thicker branched processes [37] (Figure 2A). This picture totally contrasted with WT brains that showed resting/quiescent microglia harboring a ramified morphology with slender sensing arms. We confirmed the activation status of microglia by probing for mRNA levels of the microglial activation marker A1 [38,39]. A1 mRNA levels were significantly higher in $\mathrm{CX}$ and $\mathrm{HC}$ (approximately seven-fold) of A20 KO as compared to WT mice (Figure 2B). Astrocyte activation in the brain of A20 KO mice was also evident, as demonstrated by enhanced GFAP immunoreactivity [40]. Astrocytes displaying thick cell bodies and processes characteristic of astrocyte reactivity were especially marked in the outer layers of the $\mathrm{CX}$ and throughout the $\mathrm{HC}$ (Figure 2C). Astrocyte activation was confirmed at the mRNA levels by qPCR. GFAP mRNA levels were significantly (approximately 1.8-fold) higher in the $\mathrm{CX}$ and $\mathrm{HC}$ of $\mathrm{A} 20 \mathrm{KO}$ mice as compared to WT (Figure 2D). Brains from HT mice showed an intermediate phenotype with a consistent trend for greater microglia and astrocyte activation when compared to WT mice, and for significantly lower microglia and astrocyte activation when compared to $\mathrm{KO}$ mice, as showed by IHC and qPCR (Figure 2).

Total and partial loss of A20 increases brain cytokine and chemokine levels

Activated microglia and reactive astrocytes are key defense mechanisms of the CNS to injury, in part through their ability to modulate immune and inflammatory responses by secreting pro-inflammatory cytokines and chemokines such as TNF, IL-6, IL-1 $\beta$, and MCP-1 [41,42]. As in all inflammatory responses, this defense system needs to be tightly modulated in order to avoid unfettered inflammation that would counterproductively cause neurotoxicity [43]. Accordingly, we probed by qPCR for mRNA levels of TNF, IL-6, IL-1 $\beta$ and MCP- 1 in CX and HC of A20 WT, $\mathrm{HT}$ and $\mathrm{KO}$ mice. Our results show significantly increased mRNA levels of all these pro-inflammatory mediators in the brain of $\mathrm{KO}$, as compared to WT mice, further confirming glial activation (Figure 3A). HT mouse brains also showed a tendency (albeit not significant) for higher mRNA levels of all these molecules when compared to WT brains. This tendency was more prominent in the CX than in the HC. We confirmed by IHC that higher TNF, IL-6, and MCP-1 mRNA levels in the brain of A20 deficient mice correlated with higher protein levels (Figure 3B). Double immunofluorescence staining using antibodies against microglia surface marker F4/80 or astrocyte marker GFAP in combination with anti-IL-6 demonstrate that both cell types produce IL- 6 and contribute to its increased levels in the brains of A20 KO mice (Figure 4). Altogether, these results indicate a heightened 

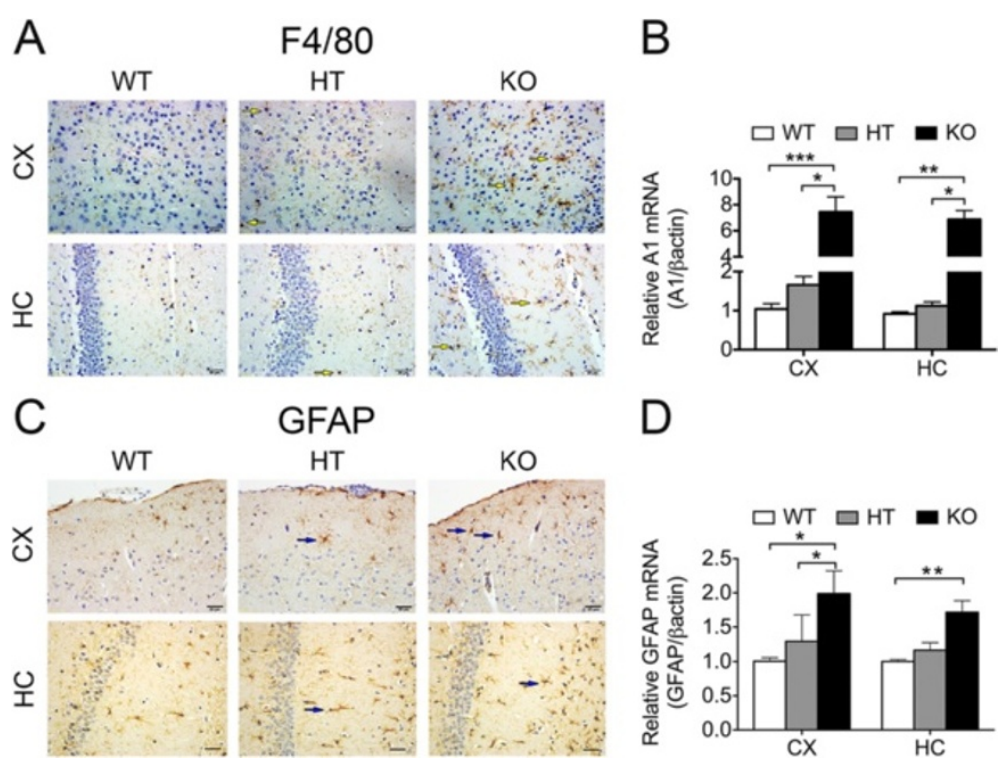

Figure 2 Loss of A20 leads to spontaneous microglia and astrocyte activation. Representative (A) F4/80 and (C) GFAP immunohistochemistry (brown) in the cerebral cortex (CX) and hippocampus (HC) of A20 wild type (WT), heterozygous (HT) and knockout (KO) mice. Yellow arrows indicate hypertrophied activated microglia, noted by their stout, dense appearance with shorter and thicker branched projections. Blue arrows indicate reactive astrocytes displaying thick cell bodies and processes, evident in the outer layers of the CX and throughout the HC. Photomicrographs are representative of three animals per genotype. Bar $=20 \mu \mathrm{m}$, magnification $=400 \mathrm{x}$. (B) A1 and (D) GFAP mRNA levels measured by qPCR. Graph shows relative mRNA levels after normalization with mRNA levels of housekeeping gene Bactin. Results are expressed as mean \pm SEM of five to seven animals per genotype. ${ }^{*} P<0.05,{ }^{* *} P<0.01$ and ${ }^{* * *} P<0.001$.

basal level of inflammation in the brain of A20 deficient mice, especially when A20 expression is totally knockedout.

Total and partial loss of A20 increases cytokine production by primary astrocytes and microglia cell line in response to pro-inflammatory stimuli

IL-6, mostly produced by astrocytes, achieves higher concentration than other soluble pro-inflammatory mediators in the brain, and hence has been designated as a key contributor to neuroinflammation $[44,45]$. To check whether enhanced IL-6 levels in the brain of A20 KO mice resulted from heightened activators, that is higher TNF levels, or also related to heightened production by A20 deficient astrocytes in response to a similar level of activator, we isolated and cultured primary astrocytes from A20 KO, HT and WT mice, exposed them for 24 hours to similar concentrations of exogenous LPS $(10 \mu \mathrm{g} / \mathrm{mL})$ and measured, by ELISA, TNF and IL-6 levels in cell culture supernatant. We noted a trend towards higher (albeit not significant) TNF and IL-6 levels in 24 hours culture supernatants of A20 KO as compared to WT astrocytes (2.25- and 1.5-fold, respectively), in the absence of any inflammatory stimuli. Following LPS treatment, TNF and IL-6 levels increased in response to LPS in all groups, albeit these levels were significantly higher in $\mathrm{KO}$, as compared to WT astrocytes (Figure 5A and B). HT astrocytes showed an intermediate response, that is LPS treatment increased IL-6 production by two to three-fold, as compared to a ten-fold upregulation in KO astrocytes (Figure 5B). Since higher LPS-induced TNF levels is the master inducer of IL-6 in astrocytes, and hence could account for higher IL-6 levels in LPS treated A20 deficient astrocytes, we independently evaluated TNF-induced production (100 $\mathrm{U} / \mathrm{ml}$ ) of IL- 6 in these cells. Here again, TNF-induced upregulation of IL- 6 production was significantly higher in A20 $\mathrm{KO}$ as compared to WT and HT astrocytes (Figure 5C). We confirmed these findings in mouse primary astrocytes that had undergone siRNA mediated A20 knockdown. Transfection of astrocytes with A20 siRNA reduced by $50 \%$ LPS-induced A20 upregulation, as evidenced by mRNA levels measured 1 hour after LPS $(1 \mu \mathrm{g} / \mathrm{mL})$ stimulation (Additional file 2: Figure S2). Inadequate A20 upregulation following LPS (mimicking A20 knockdown in A20 HT mice) correlated with significantly higher TNF and IL-6 mRNA levels six hours after LPS, as compared to levels measured in non-transfected and All Star siRNA (C siRNA) control cells (Figure 6A and B). This was paralleled by significantly higher IL- 6 protein levels in the cell culture supernatant of A20siRNA versus control cells (Figure 6C). As in astrocytes, siRNA mediated A20 knockdown in microglia cells (N13) decreased by $50 \%$ LPS induced upregulation of A20 (Additional file 2: Figure S2). Here again, this correlated with significantly higher LPS-induced upregulation of TNF and IL-6 

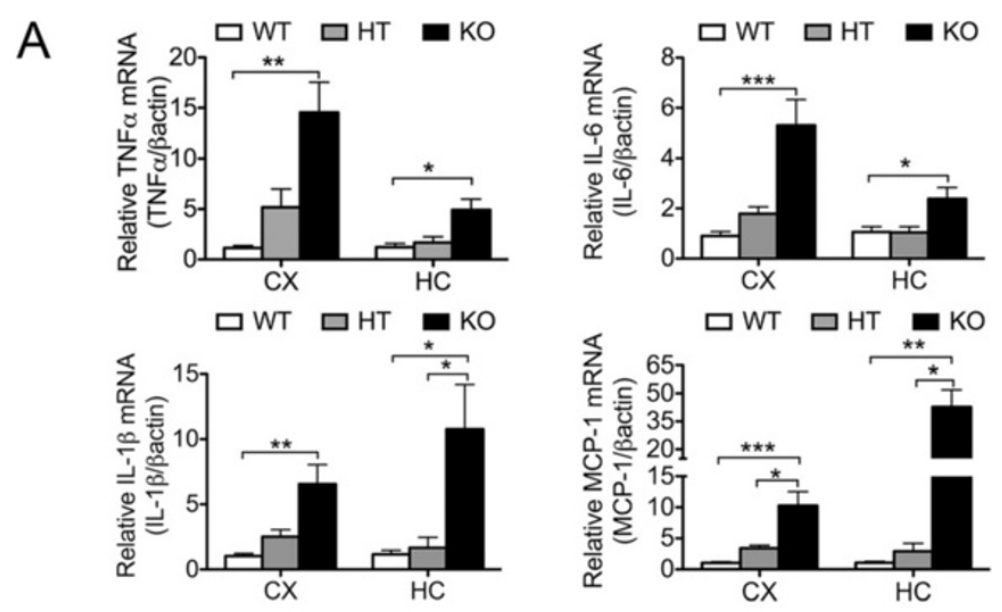

B
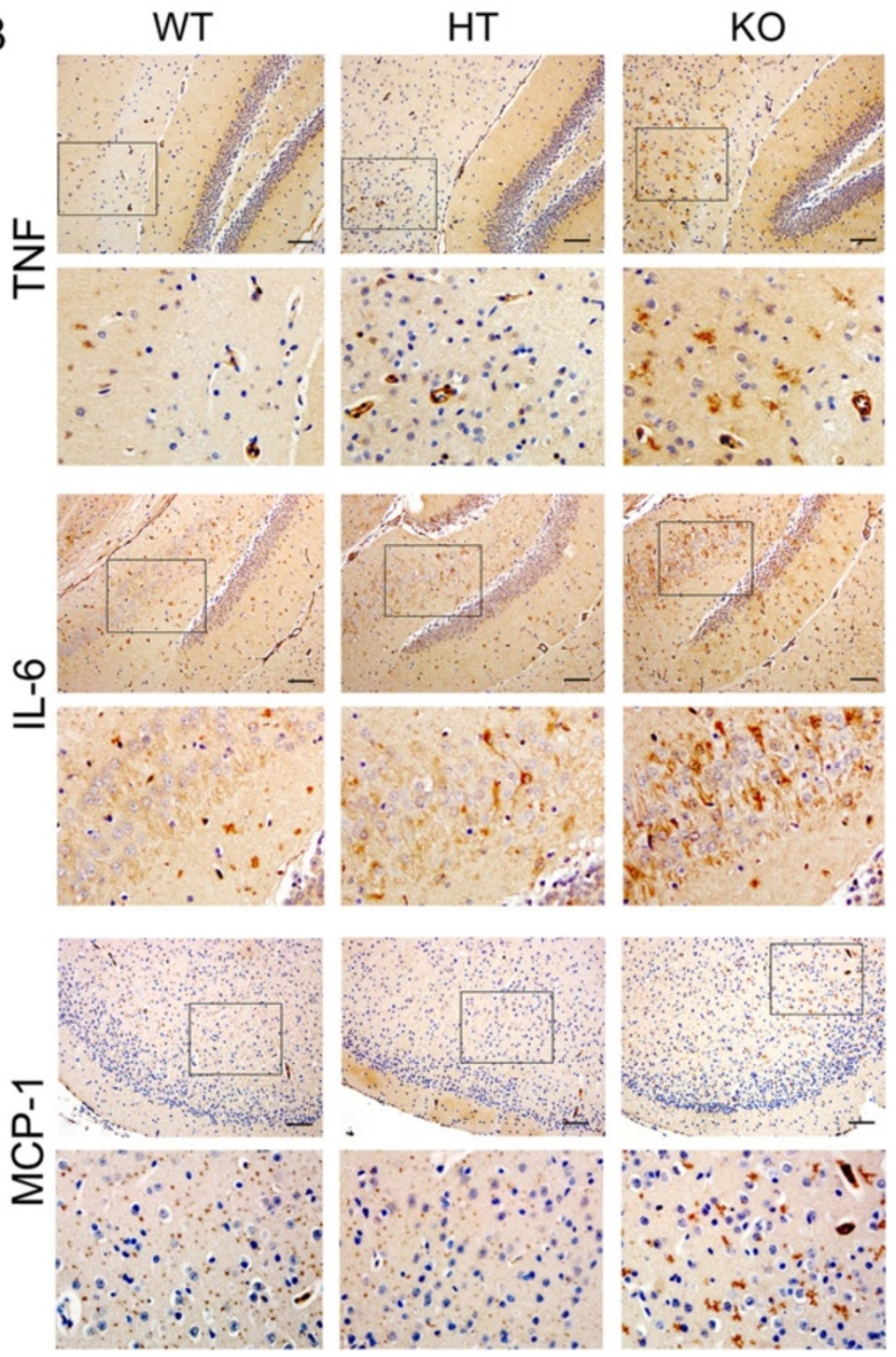

Figure 3 (See legend on next page.) 
(See figure on previous page.)

Figure 3 Levels of pro-inflammatory mediators are increased in cerebral cortex and hippocampus of A20 deficient mice. (A) TNF, IL-6, $\mathrm{IL}-1 \beta$ and MCP-1 mRNA levels in cerebral cortex (CX) and hippocampus (HC) of wild type (WT), A20 heterozygous (HT) and A20 knockout (KO), measured by qPCR. Graph shows relative mRNA levels after normalization with mRNA levels of housekeeping gene ßactin. Results are expressed as mean \pm SEM of four to seven animals per genotype. ${ }^{*} P<0.05$, ${ }^{*} P<0.01$ and ${ }^{* *} P<0.001$. (B) Representative images of TNF, IL-6 and MCP-1 immunohistochemistry (brown) in HC (TNF and IL-6) and CX (MCP-1) of A20 WT, HT and KO mice. Photomicrographs are representative of three to four animals per genotype. Top images: Bar $=50 \mu \mathrm{m}$, magnification $=200 x$. Bottom images are close-up images of the area delineated by the black box in top images.

mRNA (Figure 6D and E), and of IL-6 protein (Figure 6F) levels in these cells as compared to non-transfected or $\mathrm{C}$ siRNA transfected cells.

Altogether these results establish that both heightened activators (TNF) in brains of A20 deficient mice, and hyper-responsiveness of A20 deficient glia to pro-inflammatory stimuli contribute to the amplification of the proinflammatory spiral, culminating in excessive amount of IL-6.

Total and partial loss of A20 increases brain oxidative and nitrosative stress

NO, when produced in physiologic levels by the lowthroughput and constitutively expressed nNOS and eNOS

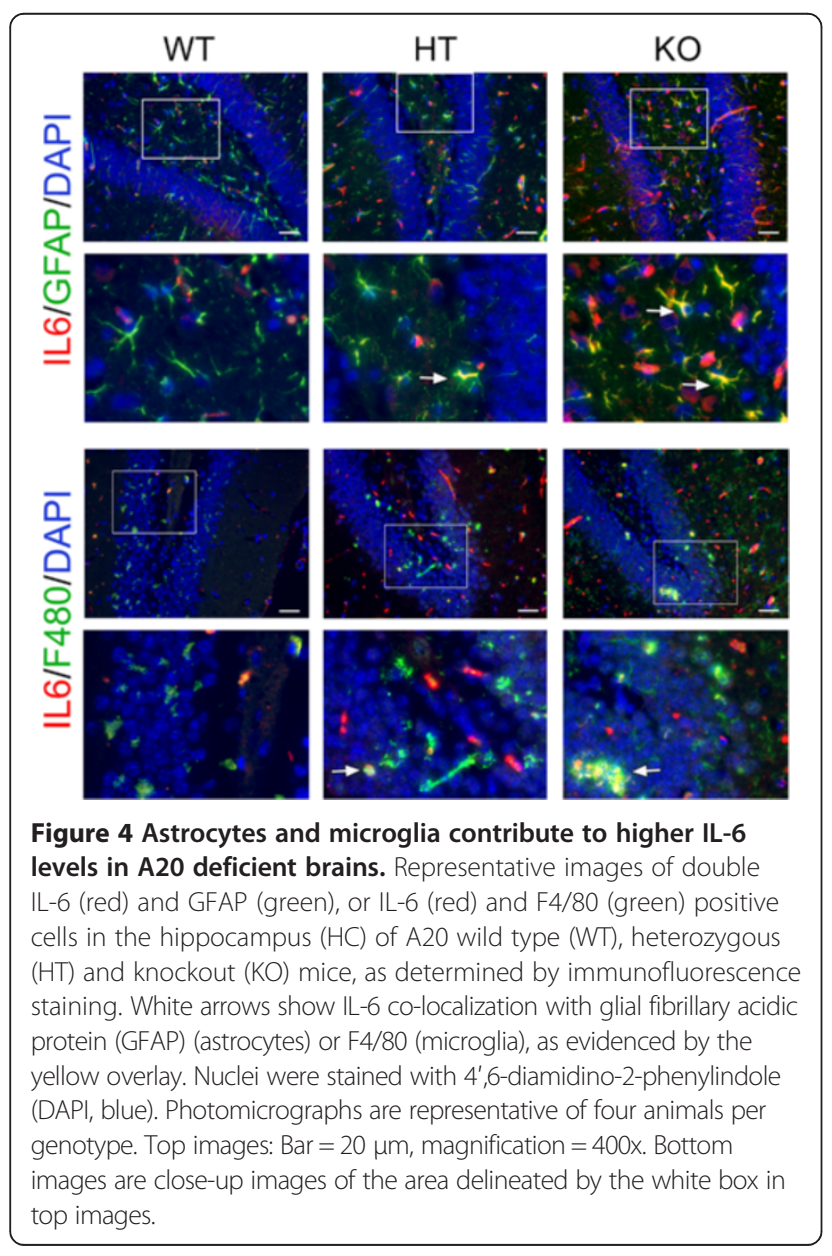

NO synthases (NOS), mostly serves a homeostatic function through regulation of synaptic signaling and plasticity $[46,47]$, as well as vasoprotection, through combined antiapoptotic, anti-inflammatory, and reactive oxygen radicals' scavenging properties [48]. However, overproduction of $\mathrm{NO}$ in pathophysiological conditions is implicated in oxidative-dependent neuronal death and dysfunction. High throughput NFkB-dependent iNOS, mainly produced by activated glia, is the primary NOS involved in inflammatory neurodegenerative disorders [49]. Accordingly, we evaluated iNOS mRNA and protein levels in $\mathrm{CX}$ and $\mathrm{HC}$ of A20-competent and A20 deficient mice. Our results show that iNOS mRNA levels significantly increase in the $\mathrm{CX}$ of $\mathrm{KO}$ mice as compared to WT, with HT demonstrating an intermediate level (Figure 7A). We confirmed this by IHC that depicted increased iNOS immunostaining in the CX of A20 deficient mice (Figure 5B). Levels of iNOS mRNA in HC were similar in all groups. Besides high NO production by iNOS, drastic increase of nNOS expression in certain pathophysiologic conditions could promote excitotoxicity causing neuronal death [50]. Interestingly, nNOS mRNA levels were significantly decreased in $\mathrm{CX}$ and $\mathrm{HC}$ of A20 KO, as compared to WT mice, with $\mathrm{HT}$ showing an intermediate phenotype (Figure 7A), while brain eNOS mRNA levels were comparable in all three genotypes (Figure 7A). Increased expression of iNOS in inflammatory conditions is often associated with increased levels of NADPH oxidase, the major enzymatic complex involved in the production of superoxide anion $\left(\mathrm{O}_{2-}^{-}\right)$[51]. Increased $\mathrm{NO}$ levels, in the setting of oxidative stress, favors formation of highly reactive peroxynitrite $\left(\mathrm{NO} / \mathrm{O}_{2}\right)$ species, enhancing formation of the protein adduct, nitrotyrosine [52]. Accordingly, we evaluated, by qPCR and Western blot, the expression level of the transmembrane catalytic subunit of NADPH oxidase, gp $91^{\text {phox }}$. Our results show that gp $91^{\text {phox }} \mathrm{mRNA}$ and protein levels were significantly higher in $\mathrm{CX}$ and $\mathrm{HC}$ of A20 KO as compared to WT and HT mice, with HT mice showing slightly higher levels then their WT littermates (Figure $7 \mathrm{C}$ and $\mathrm{D}$ ). Combined increase of gp $91^{\text {phox }}$ and iNOS (hence likely NO) production in brains of A20 KO mice correlated with increased immunostaining for nitrotyrosine, indicating heightened levels of protein nitration, implying nitrosative stress (Figure 7B). 


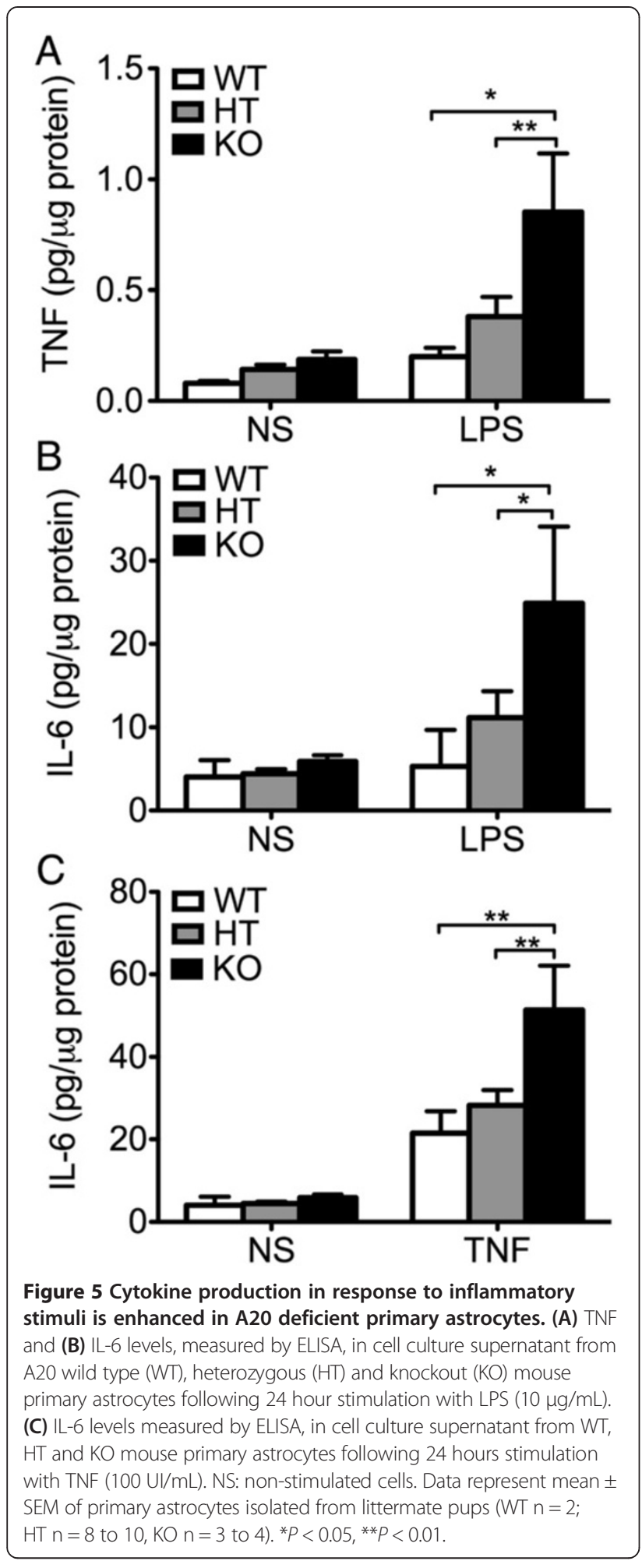

Oxidative stress in the brain is also regulated by the down-modulating effect of the transcription factor Nrf2. Nrf2 is activated in response to oxidative stress, and initiates the transcription of several antioxidant and cytoprotective genes [53,54]. Nrf2 also antagonizes inflammation in the brain by negatively impacting NFKB activation [55]. Accordingly, we checked whether A20 knockdown also increases inflammation and oxidative stress in the brain through impacting Nrf2 expression or function. Interestingly, our studies show increased Nrf2 mRNA and protein levels in A20 KO brains as compared to control (Figure 7E and F), possibly an attempt to contain oxidative stress. However, increased Nrf2 levels did not translate into any significant induction of Nrf2-dependent cytoprotective and antioxidant genes such as $\mathrm{HO}-1$ in $\mathrm{A} 20 \mathrm{KO}$ brains, suggesting that A20 knockdown likely interfered with Nrf2 activation, precluding an adequate regulatory antioxidant response in these mice (Additional file 3: Figure S3). Altogether, our results indicate that heightened inflammation in the brain of A20 deficient mice associates with enhanced oxidative and nitrosative tissue damage.

\section{Endothelial cell activation is increased in brain of A20 deficient mice}

Activation of brain EC and subsequent upregulation of adhesion and other pro-inflammatory molecules is an obligate corollary of heightened cerebral inflammation and oxidative stress, as noted in A20 KO mice [56]. Indeed, we confirmed that mRNA levels of the EC specific and prototypic activation marker, the adhesion molecule E-selectin, were significantly increased in $\mathrm{CX}$ and $\mathrm{HC}$ of A20 $\mathrm{KO}$ mice, as compared to WT, with HT fairing in between (Figure 8A). Similarly, vascular immunostaining for the adhesion molecules ICAM-1 and VCAM-1 was much stronger in brain sections of A20 KO mice, as compared to the faint staining observed in WT mice, with HT mice showing an intermediate staining (Figure $8 \mathrm{~B}$ ). These results demonstrate that A20 deficiency also caused spontaneous basal endothelial cell activation in the brain. Inflammation may results in disruption of the blood brain barrier (BBB), which allows for increased cytokine access to the brain. To evaluate whether permeability of the BBB was affected in A20 deficient mice, we intravenously injected a 2\% Evan's blue dye solution to A20 WT, HT and KO and measured the amount of dye that extravasated into the brain parenchyma. We also evaluated the integrity of the BBB by measuring serum levels of S100 calcium-binding protein $\beta$ $(\mathrm{S} 100 \beta)$, an astrocyte molecule usually released into the peripheral circulation upon disruption of these cells' membrane integrity, and a good indicator of enhanced BBB permeability [57]. Our results demonstrated that the integrity of the BBB was not altered in A20 deficient brains, despite their higher basal inflammation and EC activation levels (Additional file 4: Figure S4, Additional file 5: Supplementary Experimental Procedures).

Total and partial loss of A20 promotes axonal injury Neurofilaments (NF) are intermediate filaments of the cytoplasmic scaffold that composes the axon cytoskeleton 

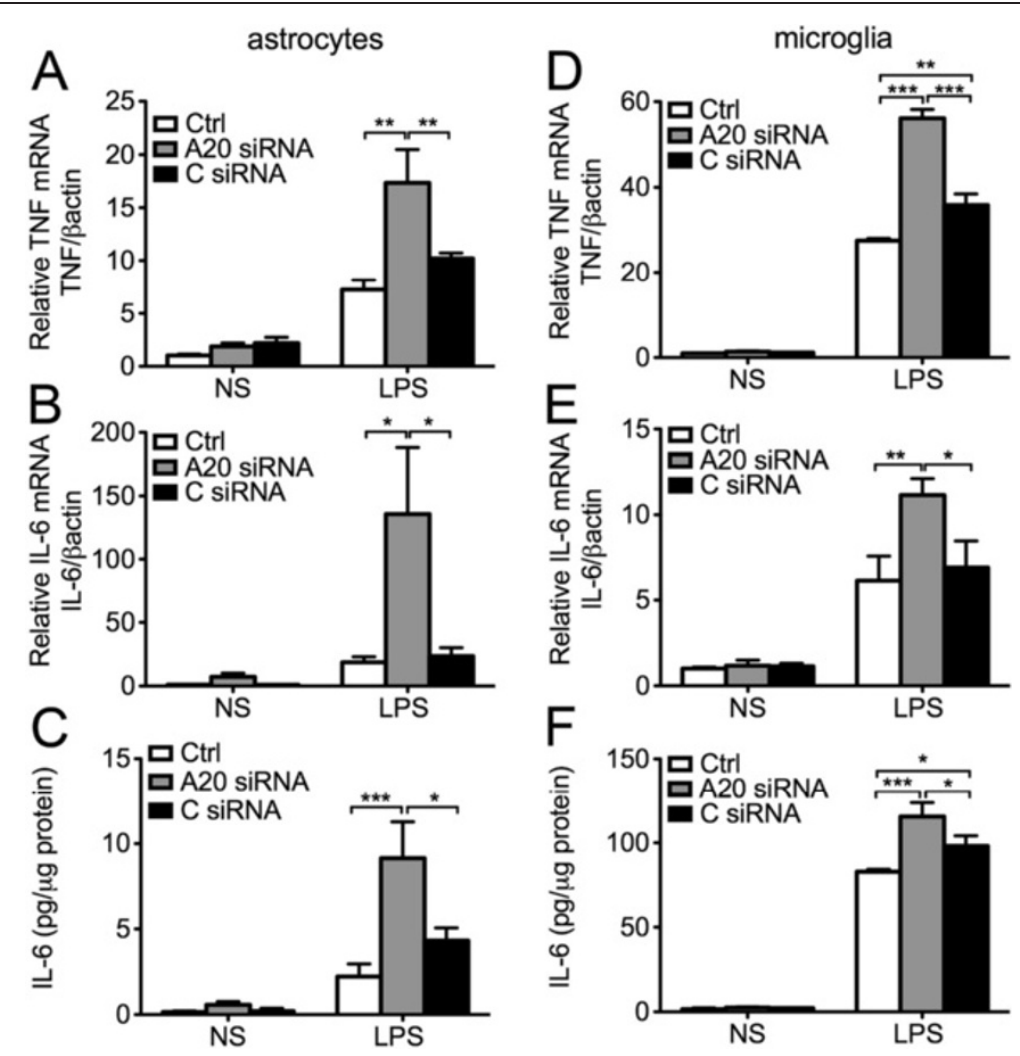

Figure 6 A20 knockdown enhances lipopolysaccharide (LPS)-mediated cytokine production in mouse primary astrocytes and microglia cell line. (A) TNF and (B) IL-6 mRNA levels in mouse primary astrocytes 6 hours after LPS (1 $\mu \mathrm{g} / \mathrm{mL})$ stimulation, as measured by qPCR. (D) TNF and (E) IL-6 mRNA levels in the microglia cell line N13, 1 hour and 6 hour respectively, after LPS (1 $\mu \mathrm{g} / \mathrm{mL})$ stimulation, as measured by qPCR. Graph shows relative mRNA levels after normalization with mRNA levels of housekeeping gene ßactin. IL-6 protein levels, measured by ELISA, in cell culture supernatant of (C) mouse primary astrocytes and (F) microglia cell line N13 6 hours after LPS (1 $\mu \mathrm{g} / \mathrm{mL})$ stimulation. Results are expressed as mean \pm SEM of three to five independent experiments. NS: non-stimulated cells. Ctrl: non-transfected control cells. A20 siRNA: cells transfected with A20 silencing RNA. C siRNA: cells transfected with All Star control silencing RNA. ${ }^{*} P<0.05,{ }^{* *} P<0.01$ and ${ }^{* * *} P<0.001$.

[58]. Expression of NF proteins decreases in physiological and pathological conditions such as aging [59], AD [60], amyotrophic lateral sclerosis and MS. Accordingly, NF protein expression levels qualify as surrogate for neuronal response to injury. Despite the fact that reduction in NF proteins is generally well tolerated [59], it is associated with decreased axonal transport velocity [61]. Brains of A20 KO mice showed significantly less immunostaining for NF (Figure 9), as compared to WT mouse brain. This is suggestive of axonal damage likely induced by chronic neuronal exposure to a pro-inflammatory environment. A20 HT mice showed an intermediate phenotype.

\section{Discussion}

A20 is a ubiquitously expressed NFKB negative feedback regulator that is highly and rapidly induced in response to $\mathrm{NF}_{\kappa} \mathrm{B}$ activation in most cell types and organs, including the human brain $[25,26]$. We demonstrated basal A20 mRNA expression in the mouse $\mathrm{CX}$ and $\mathrm{HC}$, the two brain structures that were the focus of this study, though the comparative distribution of A20 in the different brain regions varies between mice and humans [14]. We verified that basal A20 mRNA levels in CX and $\mathrm{HC}$ decreased by half and were totally absent in brains of A20 HT and KO, respectively. Lower A20 levels correlated with higher $\mathrm{NF} \kappa \mathrm{B}$ activation in the brains of A20 $\mathrm{KO}$ mice.

The inflammatory phenotype of A20 KO mice, which are cachectic and die prematurely due to uncontrolled spontaneous inflammation in the liver, kidney, joints, intestines and bone marrow, has been previously characterized [18]. However, it lacked an account of the impact of A20's deficiency on the brain. In this study, we fill this gap by showing for the first time that loss of A20 causes spontaneous cerebral inflammation, as demonstrated by robust microglial activation, reactive astrogliosis, endothelial activation, increased oxidative/nitrosative stress and expression of $\mathrm{NFK}_{\mathrm{K}} \mathrm{B}$ regulated pro-inflammatory soluble mediators such as IL- $1 \beta$, TNF, IL- 6 and MCP- 1 in the brain.

By immunostaining, using F4/80 as microglia cell surface marker, we noted the presence of a significant 

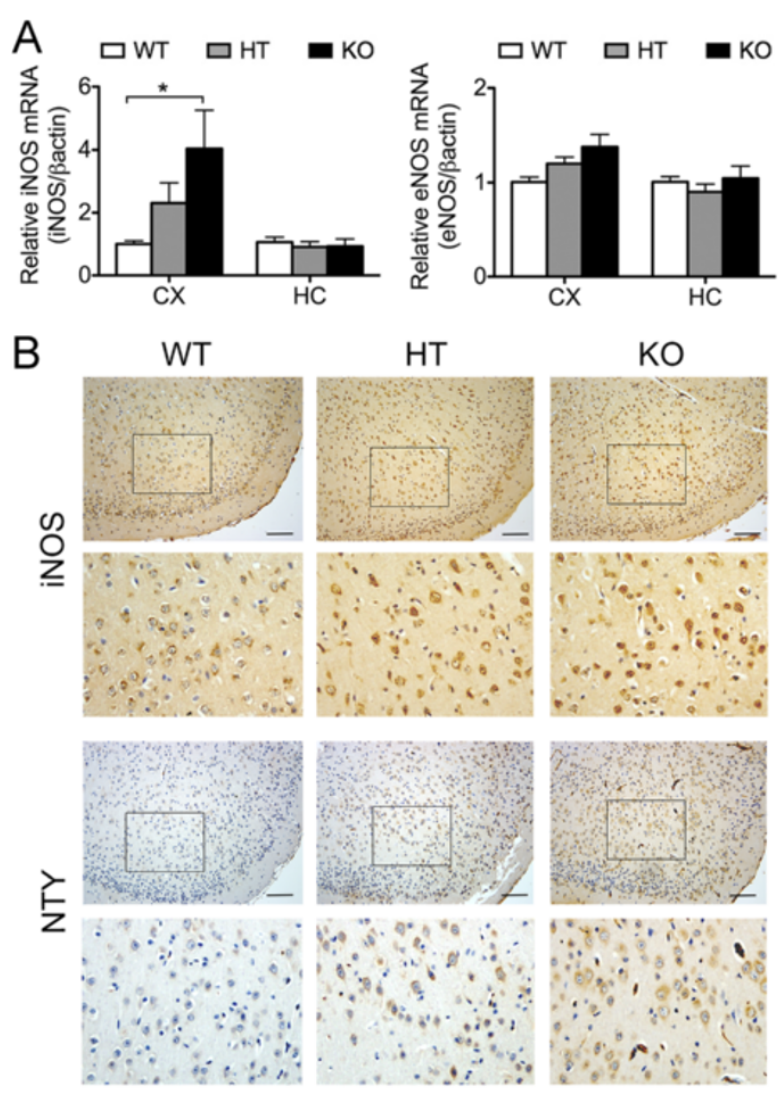

$\mathrm{E}$

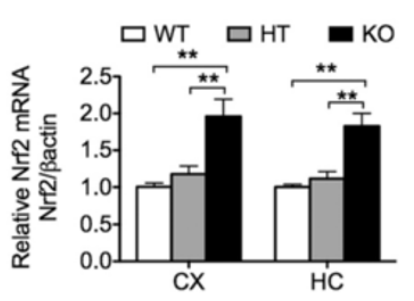

HT
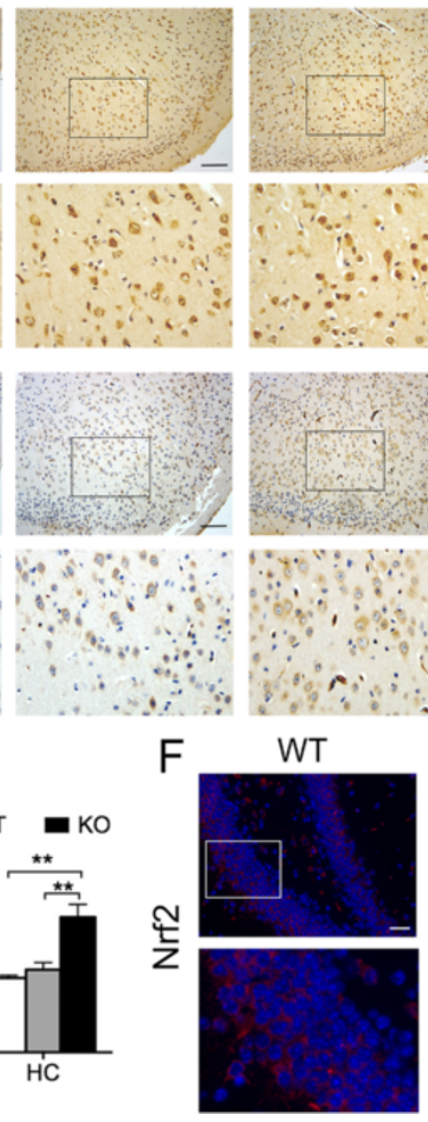

$\mathrm{KO}$
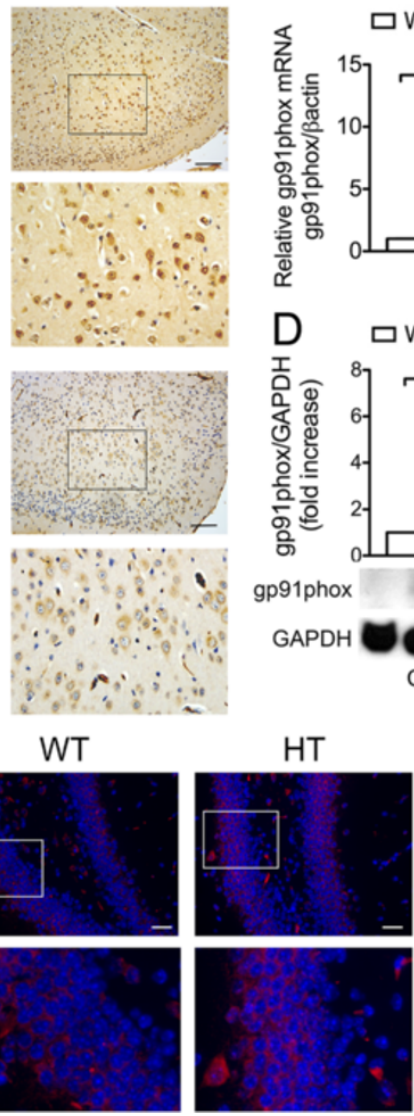

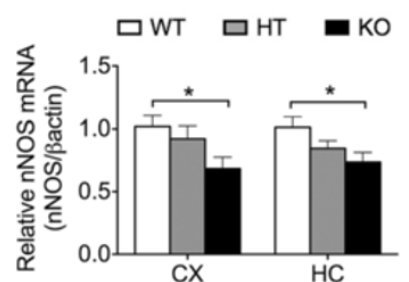

C

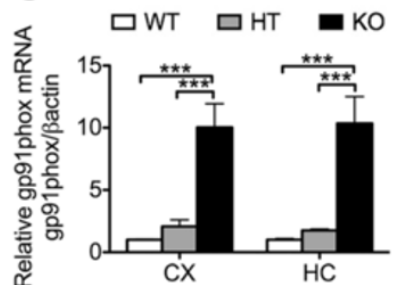

D 口ит пнт $\boldsymbol{0}$ ко
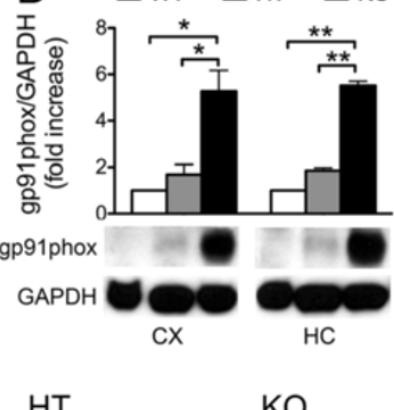

Figure 7 Loss of A20 increases oxidative/nitrosative stress in the brain. (A) iNOS, eNOS and nNOS, (C) NADPH oxidase gp91 $1^{\text {phox }}$ subunit and (E) Nrf2 mRNA levels in cerebral cortex (CX) and hippocampus (HC) of wild type (WT), A20 heterozygous (HT) and A20 knockout (KO) mice, measured by qPCR. Graphs show the statistical analysis of relative mRNA levels after normalization with ßactin. Results are expressed as mean \pm SEM of five to seven animals per genotype. (B) iNOS and nitrotyrosine (NTY) immunostaining (brown) in CX of A20 WT, HT and KO mice. Top images: Bar = 50 $\mu$ m, magnification $=200 x$. Bottom images are close-up images of the area delineated by the black box in top images. (D) NADPH oxidase gp91 ${ }^{\text {phox }}$ subunit expression in CX and HC protein lysates of A20 WT, HT and KO brains evaluated by Western blot (WB). Housekeeping protein GAPDH was used as loading control for semi-quantitative densitometry as shown in the graph. Graph shows semi-quantitative densitometry data using GAPDH as loading control. Results are expressed as mean \pm SEM for four animals per genotype. (F) Representative images of Nrf-2 (red) and 4',6-diamidino-2-phenylindole (DAPI, nuclear staining, blue) immunofluorescence staining in HC of WT, HT and KO mice. Photomicrographs are representative of three animals per genotype. Top images: Bar $=50 \mu \mathrm{m}$, magnification $=200 x$. Bottom images are close-up images of the area delineated by the white box in top images. ${ }^{*} P<0.05$ and ${ }^{* *} P<0.01$.

number of hypertrophied microglia in A20 KO brain. This cell morphology, characterized by enlarged soma and thick cytoplasmatic projecting processes with few ramifications, is typical of microglia undergoing activation after CNS injury. This microglial phenotype contrasts with that of WT brain, which is ramified resting microglia, depicting radially long and thin projecting processes with fine ramifications. We confirmed microglial activation by demonstrating heightened A1 mRNA expression in the brains of A20 KO mice, as compared to WT. Expression 

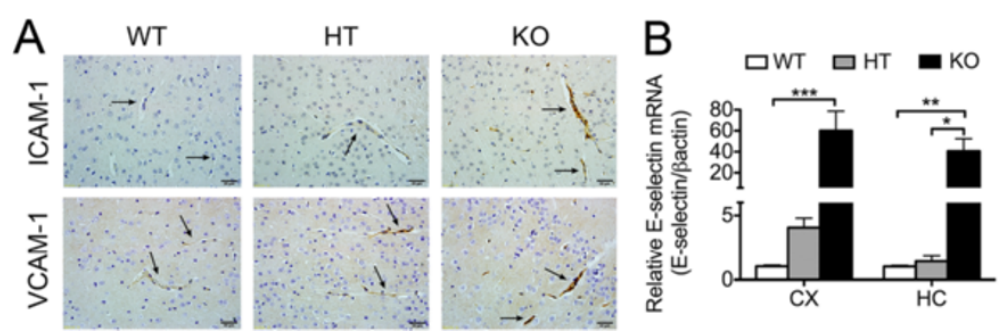

Figure 8 Expression of adhesion molecules is increased in A20 deficient brain vasculature. (A) ICAM-1 and VCAM-1 immunohistochemistry (brown) in cerebral cortex (CX) of A20 wild type (WT), heterozygous (HT) and knockout (KO) mice. Black arrows indicate blood vessels. Photomicrographs are representative of three animals per genotype. Bar $=20 \mu \mathrm{m}$, magnification $=400 \mathrm{x}$. (B) E-selectin mRNA levels in CX and hippocampus (HC) of A20 WT, HT and KO mice, measured by qPCR. Graph shows the statistical analysis of relative mRNA levels after normalization with ßactin. Results are expressed as mean \pm SEM for four to six animals per genotype. ${ }^{*} P<0.05$, ${ }^{*} P<0.01$ and ${ }^{* *} P<0.001$.

of $\mathrm{A} 1$, a $B C L 2$ gene family member, in the CNS is restricted to microglia, and is uniquely upregulated when these cells undergo activation $[38,39]$.

A20 KO brain also display enhanced astrogliosis, as morphologically evidenced by hypertrophy of astrocyte cell body and glial processes, together with increased expression of the intermediate filament GFAP, an early and sensitive biomarker of astrogliosis [62].

Furthermore, we documented in vitro that A20 deficient astrocytes and microglia are hyper reactive to inflammatory stimuli. Astrocytes isolated from A20 KO brain and

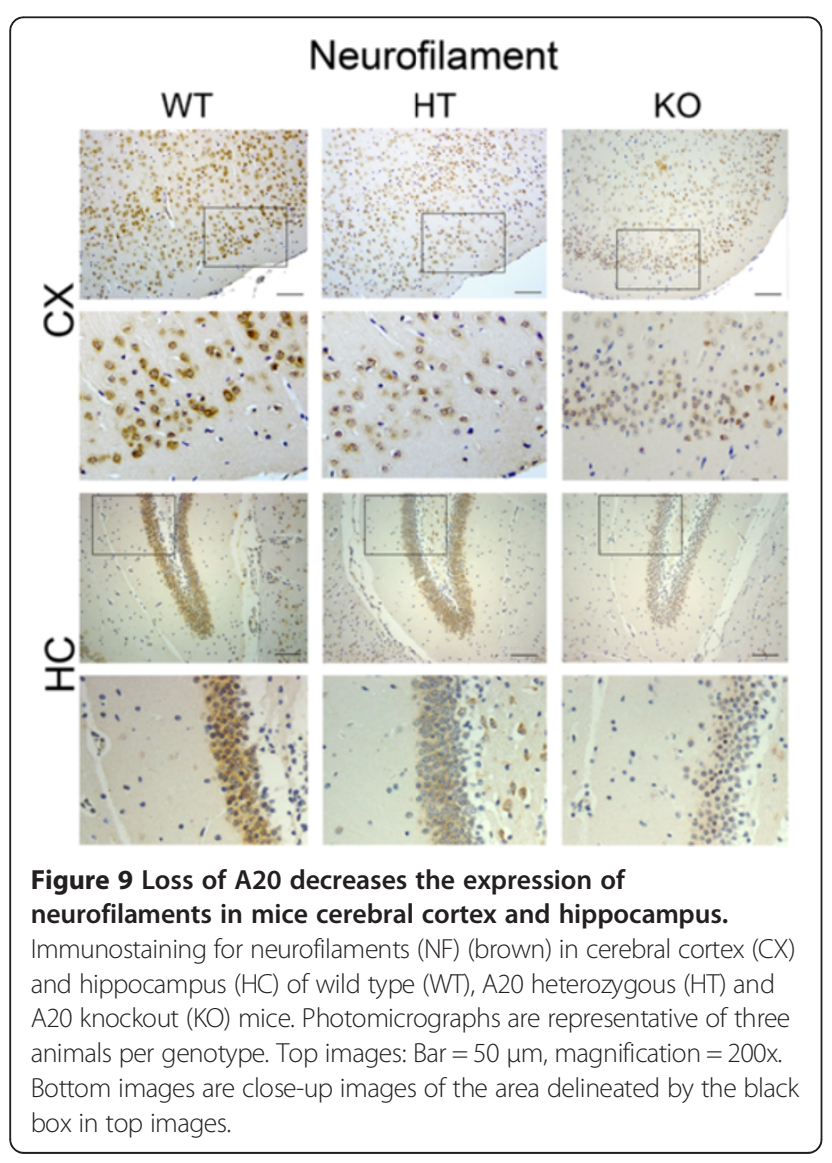

A20-silenced primary mouse astrocytes and N13 microglia cells produced significantly higher amounts of IL-6 in response to inflammatory stimuli than WT and control cells. This accords with A20 being a negative feedback regulator of inducible NFkB-dependent genes, such as IL-6 [63], and corroborates work by Wang et al. showing enhanced TNF-mediated I $\mathrm{B} \alpha \alpha$ phosphorylation/NFkB activation in A20 KO astrocytes [25]. IL-6 plays a dual role in the CNS. IL-6 KO mice that suffer compromised inflammatory responses, increased oxidative stress, impaired neuroglial activation and decreased lymphocyte recruitment, show a slower rate of recovery and healing in several models of neuroinflammatory, degenerative and traumatic brain injury [64]. On the other hand, excessively high intracerebral IL-6 levels aggravate brain injury and damage by causing abnormal immune activation, decreased neurogenesis and differentiation of neural stem/progenitor cells into neurons [64].

A20 deficient astrocytes and microglia also produced significantly higher TNF and consequently higher IL-6 levels following engagement of the Toll-like receptor (TLR) signaling by LPS treatment. Altogether, our in vivo and in vitro data ascertain the critical role of A20 in regulating glial activation. In that regard, A20 deficient glia display a similar hyper-reactive pattern to $\mathrm{A} 20 \mathrm{KO}$ peritoneal macrophages, that is sustained IкB $\alpha$ degradation and higher TNF production in response to thioglycollate or LPS treatment [65]. As a result of microglial activation and reactive astrogliosis, A20 deficient brains bathe in a heightened pro-inflammatory milieu, as evidenced by significantly higher expression of TNF, IL-1 $\beta$, IL-6 and MCP-1 in CX and HC of A20 KO mice as compared to WT.

Upregulation of the NADPH oxidase subunit gp91 $1^{\text {phox }}$ and of the high throughput NOS, iNOS, is a distinctive hallmark of glial activation [66]. Gp91 ${ }^{\text {phox }}$ deficient mice do not mount a robust ROS response following traumatic brain injury, and hence are relatively protected from cerebral damage [67]. iNOS, on the other hand, seems to have a dichotomous role in the brain. While absence of iNOS 
could impair neurogenesis after stroke, suggesting importance for CNS repair [68], excessive expression of iNOS is generally deleterious, and accordingly, genetic or pharmacologic knockdown of iNOS reduces tissue damage and neuronal death in animal models of brain injury [69,70]. Our data demonstrate that both gp91 $1^{\text {phox }}$ and iNOS expression are increased at baseline in the brain of A20 KO mice. This would result in heightened local production of $\mathrm{NO}$ and of $\mathrm{O}^{2-}$, generating highly toxic peroxynitrite radicals that promote protein nitration, particularly damaging to the CNS [71]. Indeed, we observed increased nitrotyrosine immunostaining in A20 KO when compared to WT brains. Upregulation of $\mathrm{gp} \mathrm{1}^{\text {phox }}$ and iNOS gene expression in reactive astrocytes and microglia is $\mathrm{NFKB}$ dependent [72,73], explaining their enhanced cerebral levels in the absence of A20. Importantly, NFKB activation is also a downstream target of NADPH oxidase products [72], hence the self-feeding inflammatory and pro-oxidant spiral observed in A20 KO brain. In addition, our data also suggest that A20 KO brains are unable to mount an appropriate antioxidant response, as they fail to significantly upregulate the expression of antioxidant genes such as HO-1 despite Nrf2 upregulation, which further amplifies oxidative stress, possibly causing heightened axonal damage, as suggested by decreased immunostaining for neurofilaments in $\mathrm{KO}$ brains.

Activation and loss of brain EC is another feature of inflammation driven CNS injury [74]. Maintenance of endothelial homeostasis and of the unique phenotype of the BBB depends on tight interaction between EC, perivascular glial cells and neurons via direct cell-cell contact or through soluble factors to maintain the BBB. Having demonstrated that A20 KO mice suffer important gliosis, we checked the status of brain EC in these mice. As anticipated, astrogliosis and microglial activation corresponded with overt EC activation in $\mathrm{A} 20 \mathrm{KO}$ brain vasculature, as demonstrated by increased expression of the adhesion molecules VCAM-1, ICAM-1 and endothelial specific E-selectin, as well as the chemokine MCP-1, although the latter may be a product of glial cells, in addition to EC [75]. Increased endothelial activation in brains of $\mathrm{A} 20 \mathrm{KO}$ mice is in keeping with the well-documented anti-inflammatory and homeostatic function of A20 in EC [15,76], and agrees with our recent data demonstrating that mere partial loss of A20 aggravates the inflammatory phenotype of the endothelium in a vascular allograft model of transplant arteriosclerosis (Lee et al., manuscript in preparation).

Notably, A20 KO mice analyzed in this work were not exposed to exogenous toxic substances, pathogens or surgical procedure, raising questions regarding the primary signals/mediators triggering spontaneous neuroinflammation in these mice.

Data demonstrating that spontaneous multi-organ inflammation observed in A20 KO mice resolves when the
TLR adapter MyD88 is simultaneously knocked out (A20/MyD88 double knockout), implicate pathogen-associated molecular patterns from commensal bacteria in driving the inflammatory process [77]. We hypothesize that similar mechanisms might drive spontaneous neuroinflammation in these mice. Indeed, the $\mathrm{BBB}$ may be breached in $\mathrm{A} 20 \mathrm{KO}$ and as a result, greater levels of LPS may cross the BBB and directly activate TLR expressing microglia. Alternatively, heightened EC inflammation and by consequence production of cytokines, [78,79] would engage $N F_{\kappa} B$ signaling and activate microglia [80]. Activated microglia in turn would cause reactive astrogliosis [81], creating a paracrine and autocrine feedback loop whereby microglia- and astrocytederived factors would regulate each other, promoting a self-sustained pro-inflammatory environment. We favor the latter scenario as we failed to show any significant disruption of the $\mathrm{BBB}$ in $\mathrm{A} 20 \mathrm{KO}$ mice, at least at baseline.

In contrast to our observations in whole-body A20 KO mice, astrocyte, neuronal and neuroectodermal (astrocytes, neurons and oligodendrocytes) specific A20 KO do not cause spontaneous inflammation in the CNS [25]. This suggests that A20 knockdown on microglia and/or brain EC is required to cause spontaneous inflammation of the CNS, which would agree with our hypothesis placing these two cell types at the initiation of the neuroinflammatory process. Whether specific A20 $\mathrm{KO}$ in any or both of these cells is sufficient to cause neuroinflammation, or whether $\mathrm{A} 20 \mathrm{KO}$ in all brain cells (microglia, astrocytes, neurons, oligodendrocytes, endothelial cells) is required to have the phenotype we observe remains to be determined.

Limited survival of A20 KO animals restricts our study in terms of gauging their responses in several animal models of cerebral diseases. On the other hand, our laboratory has evidence that A20 HT mice, that do not present any apparent signs of pathology, uncover a significant phenotype upon challenge. In particular, we have strong indication that partial hepatectomy, a benign procedure in WT mice, harbors high lethality in A20 HT mice (Studer et al., manuscript submitted). High lethality in these mice stems from inadequate liver regeneration that partly results from heightened inflammation. Accordingly, we set up to check the baseline brain phenotype of A20 HT mice. Interestingly, our findings show that partial loss of A20 results in mild cerebral inflammation, as demonstrated by a moderate yet consistent increase in proinflammatory and oxidative/nitrosative stress markers in the $\mathrm{CX}$ and $\mathrm{HC}$ of A20 HT mice. Those findings are highly significant, given recently described SNPs in the A20/TNFAIP3 locus, imparting decreased A20 expression or function (NFKB inhibition), that were linked with auto-immune and pro-inflammatory pathologies such as 
systemic lupus erythematosus, rheumatoid arthritis and multiple sclerosis $[82,83]$. These 'risky' TNFAIP3 SNPs, akin to those seen in A20 HT mice, may cause low-grade inflammation in the brain, predisposing patients to neuroinflammation and neurodegenerative diseases.

Neuroinflammation in brains of A20 HT mice is bound to increase with aging, and possibly metabolic diseases such as diabetes. It is well documented that microglial cells in aging brains, including those of mice, demonstrate a sensitized phenotype, that is, they release higher amounts of pro-inflammatory mediators upon activation [84]. In addition, our group has shown that A20 protein levels decrease in the context of diabetes, as a result of increased proteasomal degradation stemming from high glucose driven post-translational modifications, namely o-glycosylation and ubiquitination [85].

\section{Conclusion}

Altogether, our data uncover the cerebral phenotype of A20 deficient mice that suffer spontaneous neuroinflammation as depicted by heightened gliosis and endothelial cell activation, feeding into a spiral of local cytokine and chemokine production together with increased oxidative/ nitrosative stress, all of which culminate in neuronal damage. Future studies using A20 HT as a model for chronic spontaneous low-grade neuroinflammation may help clarify the role of A20 in brain inflammation related to aging or metabolic diseases, as well as inflammatory neurodegenerative diseases such as $\mathrm{PD}, \mathrm{AD}$, stroke or trauma.

\section{Additional files}

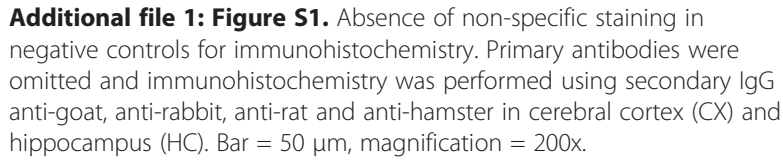

Additional file 2: Figure S2. Transfection of mouse primary astrocytes and microglia cell line N13 with A20 silencing RNA significantly reduces LPS-induced upregulation of A20 mRNA. A20 mRNA levels measured by qPCR in $\mathbf{A}$. mouse primary astrocytes and $\mathbf{B}$. microglia cell line N13 1 hour after LPS $(1 \mu \mathrm{g} / \mathrm{mL})$ stimulation. Graphs represent relative mRNA levels after normalization by ßactin. NS: non-stimulated cells. Ctrl: non-transfected control cells. A20 siRNA: cells transfected with A20 silence RNA. C siRNA: cells transfected with All Star control silence RNA. ${ }^{*} P<0.05$, ${ }^{* *} P<0.01$ and ***P $P<0.001$.

Additional file 3: Figure S3. $\mathrm{HO}-1$ levels are unchanged in cerebral cortex and hippocampus of A20 deficient mice. A. HO-1 mRNA levels in cerebral cortex (CX) and hippocampus (HC) of wild type (WT), A20 heterozygous (HT) and A20 knockout (KO) mice, measured by GPCR. Graph shows of relative RNA levels after normalization with ßactin. Results are expressed as mean \pm SEM for six to seven animals per genotype.

Additional file 4: Figure S4. Loss of A20 does not induce spontaneous changes in blood brain barrier (BBB) permeability. A. Evan's blue dye (EB) extravasation: Wild type (WT), A20 heterozygous (HT) and A20 knockout (KO) mice using were intravenously injected with 2\% EB solution. 1.5 hours after injection, animals were transcardially perfused with saline and brains were processed to measure fluorescence. Graph shows optical density (OD) at $620 \mathrm{~nm}$. B. S100 $\beta$ protein levels in serum from WT, HT and $\mathrm{KO}$ mice, measured by ELISA. Results are expressed as mean \pm SEM for three to six animals per genotype.

Additional file 5: Supplementary Experimental Procedures.

\section{Abbreviations}

AD: Alzheimer's disease; ANOVA: analysis of variance; BBB: blood brain barrier; CCL-2: chemokine (C-C motif) ligand 2; CNS: central nervous system; CX: cerebral cortex; DAB: 3,3'-diaminobenzidine tetrahydrochloride; DAPI: 4',6-diamidino-2-phenylindole; DMEM: Dulbecco's modified Eagle medium; EC: endothelial cells; ECL: enhanced chemiluminescence; ELISA: enzyme linked immunosorbent assay; eNOS: endothelial nitric oxide synthase; FBS: fetal bovine serum; GAPDH: glyceraldehyde 3-phosphate dehydrogenase; GFAP: glial fibrillary acidic protein; HC: hippocampus; HO-1: heme oxigenase-1; HRP: horseradish peroxidase; HT: heterozygous; ICAM-1: intercellular adhesion molecule-1; IF: immunofluorescence; IHC: immunohistochemistry; IL-1ß: interleukin-1 beta; IL-6: interleukin-6; iNOS: inducible nitric oxide synthase; KO: knockout; LPS: lipopolysaccharide; MCP-1: monocyte chemoattractant protein 1; MS: multiple sclerosis; NF: neurofilament; NFKB: nuclear factor kappa B; NTY: nitrotyrosine; nNOS: neuronal nitric oxide synthase; NO: nitric oxide; Nrf2: nuclear factor nuclear factor erythroid 2 related factor 2; NSAIDs: non-steroidal anti-inflammatory drugs; PD: Parkinson's disease; PVDF: polyvinylidene fluoride; qPCR: quantitative reverse transcriptase-polymerase chain reaction; S100ß: S100 calcium-binding protein beta; SDS-PAGE: sodium dodecyl sulphate-polyacrylamide gel electrophoresis; siRNA: silence RNA; SNPs: single nucleotide polymorphisms; SYBR: Sybergreen; TLR: Toll-like receptor; TNF: tumor necrosis factor alpha; TNFAIP3: tumor necrosis factor alpha-induced protein 3; VCAM-1: vascular cell adhesion protein-1; WT: wild type.

\section{Competing interests}

The authors declare that they have no competing interests.

\section{Authors' contribution}

RPG and CGS designed and performed experiments, participated in the critical analysis and interpretation of the data, performed statistical analysis of the data and wrote the manuscript. EC carried out the immunoassays (IHC). HPM carried out silence RNA experiments. CF participated in the critical analysis and interpretation of the results, contributed reagents/ materials tools and helped write the manuscript. AM generated and provided the A20 knockout mice. All authors read and approved the final manuscript.

\section{Acknowledgements}

This work was supported by NIH/NHLBI and NIH/NIDDK; Contract grant numbers: R01 HL080130, R01 DK063275 to CF. CGS is the recipient of the Eleanor and Miles Shore 50th Anniversary Fellowship Program. RPG is the recipient of a fellowship award from the National Council for Scientific and Technological Development (CNPq), Brazil. HPM was supported by the Austrian Science Fund (FWF): J3398-BW23.

\section{Author details}

${ }^{1}$ Division of Vascular Surgery, Center for Vascular Biology Research and the Transplant Institute, Department of Surgery, Beth Israel Deaconess Medical Center, Harvard Medical School, Boston, MA, USA. ${ }^{2}$ Division of Gastroenterology, University of California, San Francisco, CA, USA. ${ }^{3}$ Current address: Federal University of Health Sciences of Porto Alegre (UFCSPA), Porto Alegre, RS, Brazil.

Received: 6 February 2014 Accepted: 25 June 2014

Published: 16 July 2014

\section{References}

1. Unger JW: Glial reaction in aging and Alzheimer's disease. Microsc Res Tech 1998, 43:24-28.

2. Sawada M, Imamura K, Nagatsu T: Role of cytokines in inflammatory process in Parkinson's disease. J Neural Transm Supp/ 2006, 70:373-381.

3. Noseworthy $\mathrm{JH}$, Lucchinetti C, Rodriguez M, Weinshenker BG: Multiple sclerosis. N Engl J Med 2000, 343:938-952. 
4. Tarkowski E, Rosengren L, Blomstrand C, Wikkelso C, Jensen C, Ekholm S, Tarkowski A: Intrathecal release of pro- and anti-inflammatory cytokines during stroke. Clin Exp Immunol 1997, 110:492-499.

5. Najjar S, Pearlman DM, Alper K, Najjar A, Devinsky O: Neuroinflammation and psychiatric illness. J Neuroinflammation 2013, 10:43.

6. Depino AM: Peripheral and central inflammation in autism spectrum disorders. Mol Cell Neurosci 2013, 53:69-76.

7. Glass CK, Saijo K, Winner B, Marchetto MC, Gage FH: Mechanisms underlying inflammation in neurodegeneration. Cell 2010, 140:918-934.

8. Brown GC, Neher JJ: Inflammatory neurodegeneration and mechanisms of microglial killing of neurons. Mol Neurobiol 2010, 41:242-247.

9. De Cristobal J, Moro MA, Davalos A, Castillo J, Leza JC, Camarero J, Colado MI, Lorenzo P, Lizasoain I: Neuroprotective effect of aspirin by inhibition of glutamate release after permanent focal cerebral ischaemia in rats. J Neurochem 2001, 79:456-459.

10. Caso JR, Moro MA, Lorenzo P, Lizasoain I, Leza JC: Involvement of IL-1beta in acute stress-induced worsening of cerebral ischaemia in rats. Eur Neuropsychopharmacol 2007, 17:600-607

11. Koprich JB, Reske-Nielsen C, Mithal P, Isacson O: Neuroinflammation mediated by IL-1beta increases susceptibility of dopamine neurons to degeneration in an animal model of Parkinson's disease. J Neuroinflammation 2008, 5:8.

12. Imielski $Y$, Schwamborn JC, Luningschror $P$, Heimann $P$, Holzberg $M$, Werner $H$, Leske O, Puschel AW, Memet S, Heumann R, Israel A, Kaltschmidt C, Kaltschmidt B: Regrowing the adult brain: NF-kappaB controls functional circuit formation and tissue homeostasis in the dentate gyrus. PLoS One 2012, 7:e30838

13. Opipari AW Jr, Boguski MS, Dixit VM: The A20 cDNA induced by tumor necrosis factor alpha encodes a novel type of zinc finger protein. $J$ Biol Chem 1990, 265:14705-14708.

14. Pranski EL, Van Sanford CD, Dalal NV, Orr AL, Karmali D, Cooper DS, Costa N, Heilman CJ, Gearing M, Lah JJ, Levey Al, Betarbet RS: Comparative distribution of protein components of the A20 ubiquitin-editing complex in normal human brain. Neurosci Lett 2012, 520:104-109.

15. Cooper JT, Stroka DM, Brostjan C, Palmetshofer A, Bach FH, Ferran C: A20 blocks endothelial cell activation through a NF-kappaB-dependent mechanism. J Biol Chem 1996, 271:18068-18073.

16. Longo CR, Arvelo MB, Patel VI, Daniel S, Mahiou J, Grey ST, Ferran C: A20 protects from CD40-CD40 ligand-mediated endothelial cell activation and apoptosis. Circulation 2003, 108:1113-1118.

17. Boone DL, Turer EE, Lee EG, Ahmad RC, Wheeler MT, Tsui C, Hurley P, Chien M, Chai S, Hitotsumatsu O, McNally E, Pickart C, Ma A: The ubiquitinmodifying enzyme $A 20$ is required for termination of Toll-like receptor responses. Nat Immunol 2004, 5:1052-1060

18. Lee EG, Boone DL, Chai S, Libby SL, Chien M, Lodolce JP, Ma A: Failure to regulate TNF-induced NF-kappaB and cell death responses in A20-deficient mice. Science 2000, 289:2350-2354.

19. Daniel S, Arvelo MB, Patel VI, Longo CR, Shrikhande G, Shukri T, Mahiou J, Sun DW, Mottley C, Grey ST, Ferran C: A20 protects endothelial cells from TNF-, Fas-, and NK-mediated cell death by inhibiting caspase 8 activation. Blood 2004, 104:2376-2384.

20. Daniel S, Patel VI, Shrikhande GV, Scali ST, Ramsey HE, Csizmadia E, Benhaga N, Fisher MD, Arvelo MB, Ferran C: The universal NF-kappaB inhibitor a20 protects from transplant vasculopathy by differentially affecting apoptosis in endothelial and smooth muscle cells. Transplant Proc 2006, 38:3225-3227.

21. Damrauer SM, Studer P, Da Silva CG, Longo CR, Ramsey HE, Csizmadia E, Shrikhande GV, Scali ST, Libermann TA, Bhasin MK, Ferran C: A20 modulates lipid metabolism and energy production to promote liver regeneration. PLoS One 2011, 6:e17715.

22. Ramsey HE, Da Silva CG, Longo CR, Csizmadia E, Studer P, Patel VI, Damrauer SM, Siracuse JJ, Daniel S, Ferran C: A20 protects mice from lethal liver ischemia/reperfusion injury by increasing peroxisome proliferatoractivated receptor-alpha expression. Liver Transp/ 2009, 15:1613-1621.

23. Sunaga K, Sugaya E, Kajiwara K, Tsuda T, Sugaya A, Kimura M: Molecular mechanism of preventive effect of peony root extract on neuron damage. J Herb Pharmacother 2004, 4:9-20.

24. $Y u$ L, Miao H, Hou Y, Zhang B, Guo L: Neuroprotective effect of A20 on TNF-induced postischemic apoptosis. Neurochem Res 2006, 31:21-32.

25. Wang X, Deckert M, Xuan NT, Nishanth G, Just S, Waisman A, Naumann M, Schluter D: Astrocytic A20 ameliorates experimental autoimmune encephalomyelitis by inhibiting NF-kappaB- and STAT1-dependent chemokine production in astrocytes. Acta Neuropathol 2013, 126:711-724.

26. Mc Guire C, Rahman M, Schwaninger M, Beyaert R, van Loo G: The ubiquitin editing enzyme A20 (TNFAIP3) is upregulated during permanent middle cerebral artery occlusion but does not influence disease outcome. Cell Death Dis 2013, 4:e531.

27. Koumakis E, Giraud M, Dieude P, Cohignac V, Cuomo G, Airo P, Hachulla E, Matucci-Cerinic M, Diot E, Caramaschi P, Mouthon L, Riccieri V, Cracowski J Tiev KP, Francès C, Amoura Z, Sibilia J, Cosnes A, Carpentier P, Valentini G, Manetti M, Guiducci S, Meyer O, Kahan A, Boileau C, Chiocchia G, Allanore Y: Brief report: candidate gene study in systemic sclerosis identifies a rare and functional variant of the TNFAIP3 locus as a risk factor for polyautoimmunity. Arthritis Rheum 2012, 64:2746-2752.

28. Vereecke L, Beyaert R, van Loo G: Genetic relationships between A20/ TNFAIP3, chronic inflammation and autoimmune disease. Biochem Soc Trans 2011, 39:1086-1091.

29. Adrianto I, Wen F, Templeton A, Wiley G, King JB, Lessard CJ, Bates JS, Hu Y, Kelly JA, Kaufman KM, Guthridge JM, Alarcón Riquelme ME, BIOLUPUS and GENLES Networks, Anaya JM, Bae SC, Bang SY, Boackle SA, Brown EE, Petri MA, Gallant C, Ramsey-Goldman R, Reveille JD, Vila LM, Criswell LA, Edberg JC, Freedman Bl, Gregersen PK, Gilkeson GS, Jacob CO, James JA, et al: Association of a functional variant downstream of TNFAIP3 with systemic lupus erythematosus. Nat Genet 2011, 43:253-258.

30. Bates JS, Lessard CJ, Leon JM, Nguyen T, Battiest LJ, Rodgers J, Kaufman KM, James JA, Gilkeson GS, Kelly JA, Humphrey MB, Harley JB, Gray-McGuire C, Moser KL, Gaffney PM: Meta-analysis and imputation identifies a 109 kb risk haplotype spanning TNFAIP3 associated with lupus nephritis and hematologic manifestations. Genes Immun 2009, 10:470-477.

31. McCarthy KD, de Vellis J: Preparation of separate astroglial and oligodendroglial cell cultures from rat cerebral tissue. J Cell Biol 1980, 85:890-902

32. Laemmli UK: Cleavage of structural proteins during the assembly of the head of bacteriophage T4. Nature 1970, 227:680-685.

33. Csizmadia E, Csizmadia V: Detection of apoptosis in tissue sections. Methods Mol Biol 2009, 559:49-63.

34. Block ML, Zecca L, Hong JS: Microglia-mediated neurotoxicity: uncovering the molecular mechanisms. Nat Rev Neurosci 2007, 8:57-69.

35. Zhang D, Hu X, Qian L, O'Callaghan JP, Hong JS: Astrogliosis in CNS pathologies: is there a role for microglia? Mol Neurobiol 2010, 41:232-241.

36. Moussaud S, Draheim HJ: A new method to isolate microglia from adult mice and culture them for an extended period of time. J Neurosci Methods 2010, 187:243-253.

37. He J, Crews FT: Increased MCP-1 and microglia in various regions of the human alcoholic brain. Exp Neurol 2008, 210:349-358.

38. Zhang L, Nair A, Krady K, Corpe C, Bonneau RH, Simpson IA, Vannucci SJ: Estrogen stimulates microglia and brain recovery from hypoxia-ischemia in normoglycemic but not diabetic female mice. J Clin Invest 2004, 113:85-95

39. Kumari R, Willing LB, Krady JK, Vannucci SJ, Simpson IA: Impaired wound healing after cerebral hypoxia-ischemia in the diabetic mouse. J Cereb Blood Flow Metab 2007, 27:710-718.

40. Eng LF, Ghirnikar RS: GFAP and astrogliosis. Brain Pathol 1994, 4:229-237.

41. Farina C, Aloisi F, Meinl E: Astrocytes are active players in cerebral innate immunity. Trends Immunol 2007, 28:138-145.

42. Semple BD, Kossmann T, Morganti-Kossmann MC: Role of chemokines in CNS health and pathology: a focus on the CCL2/CCR2 and CXCL8/CXCR2 networks. J Cereb Blood Flow Metab 2010, 30:459-473.

43. Harry GJ, Kraft AD: Neuroinflammation and microglia: considerations and approaches for neurotoxicity assessment. Expert Opin Drug Metab Toxicol 2008, 4:1265-1277.

44. Dong Y, Benveniste EN: Immune function of astrocytes. Glia 2001, 36:180-190.

45. Aloisi F, Care A, Borsellino G, Gallo P, Rosa S, Bassani A, Cabibbo A, Testa U, Levi G, Peschle C: Production of hemolymphopoietic cytokines (IL-6, IL-8, colony-stimulating factors) by normal human astrocytes in response to IL-1 beta and tumor necrosis factor-alpha. J Immunol 1992, 149:2358-2366.

46. Zhou L, Zhu DY: Neuronal nitric oxide synthase: structure, subcellular localization, regulation, and clinical implications. Nitric Oxide 2009, 20:223-230

47. Mungrue IN, Bredt DS: nNOS at a glance: implications for brain and brawn. J Cell Sci 2004, 117:2627-2629. 
48. Endres M, Laufs U, Liao JK, Moskowitz MA: Targeting eNOS for stroke protection. Trends Neurosci 2004, 27:283-289.

49. Murphy S: Production of nitric oxide by glial cells: regulation and potential roles in the CNS. Glia 2000, 29:1-13.

50. Bolanos JP, Almeida A, Stewart V, Peuchen S, Land JM, Clark JB, Heales SJ: Nitric oxide-mediated mitochondrial damage in the brain: mechanisms and implications for neurodegenerative diseases. J Neurochem 1997, 68:2227-2240

51. Mander P, Brown GC: Activation of microglial NADPH oxidase is synergistic with glial iNOS expression in inducing neuronal death: a dual-key mechanism of inflammatory neurodegeneration. J Neuroinflammation 2005, 2:20

52. Reiter CD, Teng RJ, Beckman JS: Superoxide reacts with nitric oxide to nitrate tyrosine at physiological pH via peroxynitrite. J Biol Chem 2000, 275:32460-32466.

53. Itoh K, Igarashi K, Hayashi N, Nishizawa M, Yamamoto M: Cloning and characterization of a novel erythroid cell-derived CNC family transcription factor heterodimerizing with the small Maf family proteins. Mol Cell Biol 1995, 15:4184-4193.

54. de Vries HE, Witte M, Hondius D, Rozemuller AJ, Drukarch B, Hoozemans J, van Horssen J: Nrf2-induced antioxidant protection: a promising target to counteract ROS-mediated damage in neurodegenerative disease? Free Radic Biol Med 2008, 45:1375-1383.

55. Li W, Khor TO, Xu C, Shen G, Jeong WS, Yu S, Kong AN: Activation of Nrf2-antioxidant signaling attenuates NFkappaB-inflammatory response and elicits apoptosis. Biochem Pharmacol 2008, 76:1485-1489.

56. Radisavljevic Z, Avraham H, Avraham S: Vascular endothelial growth factor up-regulates ICAM-1 expression via the phosphatidylinositol $3 \mathrm{OH}$-kinase/AKT/Nitric oxide pathway and modulates migration of brain microvascular endothelial cells. J Biol Chem 2000, 275:20770-20774.

57. Berger RP, Adelson PD, Pierce MC, Dulani T, Cassidy LD, Kochanek PM: Serum neuron-specific enolase, S100B, and myelin basic protein concentrations after inflicted and noninflicted traumatic brain injury in children. J Neurosurg 2005, 103:61-68.

58. Fuchs $\mathrm{E}$, Cleveland DW: A structural scaffolding of intermediate filaments in health and disease. Science 1998, 279:514-519.

59. Kuchel GA, Poon T, Irshad K, Richard C, Julien JP, Cowen T: Decreased neurofilament gene expression is an index of selective axonal hypotrophy in ageing. Neuroreport 1996, 7:1353-1359.

60. Somerville MJ, Percy ME, Bergeron C, Yoong LK, Grima EA, McLachlan DR: Localization and quantitation of $68 \mathrm{kDa}$ neurofilament and superoxide dismutase-1 mRNA in Alzheimer brains. Brain Res Mol Brain Res 1991, 9:1-8.

61. McKerracher L, Vidal-Sanz M, Essagian C, Aguayo AJ: Selective impairment of slow axonal transport after optic nerve injury in adult rats. J Neurosci 1990, 10:2834-2841.

62. O'Callaghan JP, Sriram K: Glial fibrillary acidic protein and related glial proteins as biomarkers of neurotoxicity. Expert Opin Drug Saf 2005, 4:433-442.

63. da Silva CG, Studer P, Skroch M, Mahiou J, Minussi DC, Peterson CR, Wilson SW, Patel VI, Ma A, Csizmadia E, Ferran C: A20 promotes liver regeneration by decreasing SOCS3 expression to enhance IL-6/STAT3 proliferative signals. Hepatology 2013, 57:2014-2025.

64. Erta M, Quintana A, Hidalgo J: Interleukin-6, a major cytokine in the central nervous system. Int J Biol Sci 2012, 8:1254-1266.

65. Matmati M, Jacques P, Maelfait J, Verheugen E, Kool M, Sze M, Geboes L, Louagie E, Mc Guire C, Vereecke L, Chu Y, Boon L, Staelens S, Matthys P, Lambrecht BN, Schimidt-Supprian M, Pasparakis M, Elewaut D, Beyaert R, van Loo G: A20 (TNFAIP3) deficiency in myeloid cells triggers erosive polyarthritis resembling rheumatoid arthritis. Nat Genet 2011, 43:908-912.

66. Cheret C, Gervais A, Lelli A, Colin C, Amar L, Ravassard P, Mallet J, Cumano A, Krause $\mathrm{KH}$, Mallat M: Neurotoxic activation of microglia is promoted by a nox1-dependent NADPH oxidase. J Neurosci 2008, 28:12039-12051.

67. Dohi K, Ohtaki H, Nakamachi T, Yofu S, Satoh K, Miyamoto K, Song D, Tsunawaki S, Shioda S, Aruga T: Gp91 phox (NOX2) in classically activated microglia exacerbates traumatic brain injury. J Neuroinflammation 2010, 7:41.

68. Zhu DY, Liu SH, Sun HS, Lu YM: Expression of inducible nitric oxide synthase after focal cerebral ischemia stimulates neurogenesis in the adult rodent dentate gyrus. J Neurosci 2003, 23:223-229.
69. Ono K, Suzuki H, Sawada M: Delayed neural damage is induced by iNOS-expressing microglia in a brain injury model. Neurosci Lett 2010, 473:146-150.

70. ladecola C, Zhang F, Xu X: Inhibition of inducible nitric oxide synthase ameliorates cerebral ischemic damage. Am J Physiol 1995, 268:R286-R292.

71. Phares TW, Fabis MJ, Brimer CM, Kean RB, Hooper DC: A peroxynitritedependent pathway is responsible for blood-brain barrier permeability changes during a central nervous system inflammatory response: TNF-alpha is neither necessary nor sufficient. J Immunol 2007, 178:7334-7343.

72. Anrather J, Racchumi G, ladecola C: NF-kappaB regulates phagocytic NADPH oxidase by inducing the expression of gp91phox. J Biol Chem 2006, 281:5657-5667.

73. Saha RN, Pahan K: Regulation of inducible nitric oxide synthase gene in glial cells. Antioxid Redox Signal 2006, 8:929-947.

74. Krizanac-Bengez L, Mayberg MR, Janigro D: The cerebral vasculature as a therapeutic target for neurological disorders and the role of shear stress in vascular homeostatis and pathophysiology. Neurol Res 2004, 26:846-853.

75. Tei N, Tanaka J, Sugimoto K, Nishihara T, Nishioka R, Takahashi H, Yano H, Matsumoto S, Ohue S, Watanabe H, Kumon Y, Ohnishi T: Expression of MCP-1 and fractalkine on endothelial cells and astrocytes may contribute to the invasion and migration of brain macrophages in ischemic rat brain lesions. J Neurosci Res 2013, 91:681-693.

76. Ferran C, Stroka DM, Badrichani AZ, Cooper JT, Wrighton CJ, Soares M, Grey ST, Bach FH: A20 inhibits NF-kappaB activation in endothelial cells without sensitizing to tumor necrosis factor-mediated apoptosis. Blood 1998, 91:2249-2258.

77. Turer EE, Tavares RM, Mortier E, Hitotsumatsu O, Advincula R, Lee B, Shifrin $\mathrm{N}$, Malynn BA, Ma A: Homeostatic MyD88-dependent signals cause lethal inflammation in the absence of A20. J Exp Med 2008, 205:451-464.

78. Caso JR, Pradillo JM, Hurtado O, Lorenzo P, Moro MA, Lizasoain I: Toll-like receptor 4 is involved in brain damage and inflammation after experimental stroke. Circulation 2007, 115:1599-1608.

79. Chakravarty S, Herkenham M: Toll-like receptor 4 on nonhematopoietic cells sustains CNS inflammation during endotoxemia, independent of systemic cytokines. J Neurosci 2005, 25:1788-1796.

80. Rivest S: Regulation of innate immune responses in the brain. Nat Rev Immunol 2009, 9:429-439.

81. Saijo K, Winner B, Carson CT, Collier JG, Boyer L, Rosenfeld MG, Gage FH, Glass CK: A Nurr1/CoREST pathway in microglia and astrocytes protects dopaminergic neurons from inflammation-induced death. Cell 2009, 137:47-59.

82. Dieguez-Gonzalez R, Calaza M, Perez-Pampin E, Balsa A, Blanco FJ, Canete JD, Caliz R, Carreno L, de la Serna AR, Fernandez-Gutierrez B, Ortiz AM, HerreroBeaumont G, Pablos JL, Narvaez J, Navarro F, Marenco JL, Gomez_reino JJ, Gonzales A: Analysis of TNFAIP3, a feedback inhibitor of nuclear factorkappaB and the neighbor intergenic $6 q 23$ region in rheumatoid arthritis susceptibility. Arthritis Res Ther 2009, 11:R42.

83. Musone SL, Taylor KE, Lu TT, Nititham J, Ferreira RC, Ortmann W, Shifrin N, Petri MA, Kamboh MI, Manzi S, Seldin MF, Gregersen PK, Behrens TW, Ma A, Kwok PY, Criswell LA: Multiple polymorphisms in the TNFAIP3 region are independently associated with systemic lupus erythematosus. Nat Genet 2008, 40:1062-1064

84. Jurgens HA, Johnson RW: Dysregulated neuronal-microglial cross-talk during aging, stress and inflammation. Exp Neurol 2010, 1:40-48.

85. Shrikhande GV, Scali ST, da Silva CG, Damrauer SM, Csizmadia E, Putheti P, Matthey M, Arjoon R, Patel R, Siracuse JJ, Maccariello ER, Andersen ND, Monahan T, Peterson C, Essayagh S, Studer P, Guedes RP, Kocher O, Usheva A, Veves A, Kaczmarek E, Ferran C: O-glycosylation regulates ubiquitination and degradation of the anti-inflammatory protein $\mathrm{A} 20$ to accelerate atherosclerosis in diabetic ApoE-null mice. PLoS One 2010, 5:e14240.

doi:10.1186/1742-2094-11-122

Cite this article as: Guedes et al:: A20 deficiency causes spontaneous neuroinflammation in mice. Journal of Neuroinflammation 2014 11:122. 